J) Tampere University

TAMPERE ECONOMIC WORKING PAPERS

SCREENING THROUGH ACTIVATION? DIFFERENTIAL EFFECTS OF A YOUTH ACTIVATION PROGRAM

\author{
Caroline Hall \\ Kaisa Kotakorpi \\ Linus Liljeberg \\ Jukka Pirttilä
}

Working Paper 130

June 2020

FACULTY OF MANAGEMENT AND BUSINESS

FI-33014 TAMPERE UNIVERSITY, FINLAND

ISSN 1458-1191

ISBN 978-952-03-1609-9 (pdf) 


\title{
Screening through Activation? Differential Effects of a Youth Activation Program
}

Caroline Hall, Kaisa Kotakorpi, Linus Liljeberg and Jukka Pirttilä

\begin{abstract}
We study the dual role of active labor market policies: First, ALMP may perform a screening role by increasing job-search incentives, especially among individuals with good labor market prospects, already before program participation. Second, actual program participation may help individuals with poor labor market prospects. We examine whether this type of pattern can be found in individual responses to a nationwide youth activation program in Sweden using an RD-design. We find that individuals with a high predicted probability of finding work respond to the threat of activation, whereas there is no effect for individuals with weak labor market prospects.
\end{abstract}

Caroline Hall is a researcher and associate professor at IFAU and Uppsala Center for Labour Studies (UCLS); e-mail: caroline.hall@ifau.uu.se.

Kaisa Kotakorpi is a professor at Tampere University and VATT Institute for Economic Research. Linus Liljeberg is a research officer at IFAU.

Jukka Pirttilä is a professor at University of Helsinki, VATT Institute for Economic Research, and Helsinki GSE.

We are grateful to two anonymous referees for their useful comments and suggestions. We also thank Mike Brewer, Matz Dahlberg, Peter Fredriksson, Tomi Kyyrä, Martin Lundin, Eva Mörk, Miikka Rokkanen, Matti Sarvimäki, Jouko Verho, participants at the IIPF Annual Congress 2014, 
IZA/IFAU conference on Labour Market Policy Evaluation 2014, CESifo Area Conference on Employment and Social Protection 2015, $2^{\text {nd }}$ NORFACE 4Is Workshop 2016, EEA Congress 2016 and seminar participants at the University of Copenhagen, KU Leuven, IFAU, HECER, the Labour Institute for Economic Research, the National Institute for Health and Welfare, and the University of Turku for their valuable comments.

The paper is based on total population administrative data including sensitive information (health data) that we are not allowed to share. The data and program files necessary for replication can be obtained by contacting ifau@ifau.uu.se.

Funding from the Academy of Finland (Grant No. 252369), the Swedish Research Council for Health, Working Life and Welfare (FORTE, Grant No. 2011-1045), NORFACE (Grant No. 462-14013) and the Yrjö Jahnsson Foundation is gratefully acknowledged.

JEL-codes: J64, J68, I10 


\section{Introduction}

We examine empirically whether activation of the unemployed affects job finding rates mainly through helping those with otherwise poor labor market prospects to find work, or through persuading individuals with generally good labor market prospects to search more intensively for a job. The latter phenomenon would indicate that active labor market programs have a screening role, similar to the screening effect of workfare discussed in theoretical work initially in the context of poverty alleviation; the seminal contribution here is Besley and Coate (1992). ${ }^{1}$ Such an effect is related to the so-called threat effect of active labor market programs (e.g. Black et al. 2003), whereby individuals respond to the presence of a program already prior to actual participation. However, in the presence of screening, the threat effect is heterogeneous in such a way that it affects precisely those individuals with good labor market prospects. Despite a number of theoretical papers analyzing the screening role of workfare, direct empirical evidence remains limited.

We analyze the pattern of individual responses to a major, nationwide youth activation program (the Youth Job Guarantee) that was introduced in Sweden in 2007. The focus of the program was on activities related to job search. We use data for the entire Swedish population and covering the universe of unemployment spells during the period under study. Before turning to the empirical analysis, we illustrate how the screening effect may arise in a search theory framework where individuals differ in their labor market prospects.

Another distinguishing feature of our analysis is that in looking at the screening role and the heterogeneous effects of activation, we are able to focus on a particularly rich set of background variables. In addition to more traditional background variables such as education and immigrant status, we have exceptionally good data on the individuals' past health and labor market history. The use of health data is motivated by the finding that individuals with 
poor past health - especially those with past mental health problems - are overrepresented among individuals with poor labor market prospects.

To study heterogeneous effects of the program, we first classify individuals according to their predicted probability of finding work. We do this by using an empirical model estimated on out-of-sample data (data on unemployment spells in the year prior to the introduction of the program). This simple approach avoids the problem of endogenous stratification that has been present in some earlier studies, as pointed out by Abadie, Chingos, and West (2016). Individuals with a relatively high predicted probability of finding work are then classified as being in a relatively strong labor market position, and therefore more likely to be voluntarily unemployed.

We use a regression discontinuity (RD) design to estimate the effects of the Youth Job Guarantee program (YJG), using the fact that only individuals under 25 years of age are eligible for the program. Under 25-year-olds are eligible if they have been unemployed for more than 90 days. Thus, our empirical strategy is essentially to compare the job-finding rate among individuals who have just turned 25 before 90 days of unemployment (ineligible) to the job-finding rate among those who are just below age 25 at 90 days of unemployment (eligible). We analyze the effect of program eligibility on the probability of finding employment during the first 90 days of the unemployment spell (the threat effect) as well as at different points in time later on, both for all unemployed persons and separately for subgroups defined by their labor market prospects.

There is extensive earlier literature on the effects of active labor market programs (ALMP), see e.g. Card, Kluve, and Weber (2018) and Kluve et al. (2019) for recent reviews. The most relevant studies for our paper are reviewed in Section II. We contribute to this literature in a number of ways. First, we provide evidence on the screening role of activation programs by examining how the effects of activation differ with respect to individuals' labor market 
prospects. While there are numerous theoretical papers on the screening effect of workfare/ALMP in different types of settings, we are not aware of earlier empirical evidence focusing directly on this issue. We study whether the pattern of exit (both regarding the timing as well as heterogeneity across individuals) from unemployment in response to the introduction of an activation program is consistent with the idea that ALMP screens away from unemployment those individuals whom we would predict to have a good chance of finding a job even in the absence of activation. We also provide a brief conceptual framework that illustrates how the screening effect may arise in a labor market search model where individuals differ in their baseline probabilities of finding work. As we argue in Section II, previous theoretical applications do not analyze the role of screening in the context of transitions from unemployment to work. Second, only a few studies examine whether activation programs have different impacts among disadvantaged youth. Disadvantaged youth is an important group to look at, since preventing social exclusion is often a key motivation behind programs targeted at youth. In the previous literature, disadvantageousness is generally proxied by level of education, whereas we use a rich set of background information including extensive knowledge of individuals' past unemployment history and health. Finally, one of the conclusions in Kluve et al. (2019) is that many employment programs targeting youth in high-income countries appear to fail to achieve positive effects. It is of interest in itself to evaluate whether the large, nationwide Swedish activation program yields more promising outcomes.

Our results show that there is a statistically significant threat effect associated with the program: Program eligibility increases the probability of finding employment before the program starts by around 6 percent. Our results also indicate that the threat effect is mainly driven by groups with a more advantaged position in the labor market - we find no statistically significant effects for the group with the weakest labor market prospects. 
Moreover, we do not find any long-term effects of the program for any group: within a year from the start of unemployment, job-finding rates among the ineligible seem to have caught up with those of the eligible. The empirical patterns that we find are consistent with the idea that the program performs a screening role. The main effect of the program appears to be to screen away from unemployment some individuals who are able to find work on their own, whereas there appear to be no positive effects for those in a poorer labor market position. Job match quality, measured by subsequent earnings and wages, does not appear to be affected by the program.

The paper proceeds as follows. Section II provides the theoretical background for our empirical analysis, and it also discusses earlier empirical work in the area. Section III describes the activation program, while the data is described in Section IV. The empirical methodology and the results for the whole sample as well as for the subgroups are presented in Section V. We also conduct a large battery of RD validity and robustness checks. In Section VI we assess the impact on the government budget, and Section VII concludes.

\section{Background and Earlier Literature}

\section{A. Theoretical background}

Besley and Coate (1992) provided a seminal theoretical contribution on the screening role of workfare, arguing that work requirements in poverty alleviation programs can function as a screening device between those who are truly in need of poor support and those who are not. ${ }^{2}$ The result arises because high-ability individuals have a higher opportunity cost of time and are therefore less willing to participate in workfare programs. Kreiner and Tranaes (2005) provide a theoretical analysis of the screening role of workfare in the labor market context, and a similar model has been studied in Fredriksson and Holmlund (2006a). In this model, individuals who are voluntarily unemployed (or "non-workers" in their terminology) have a 
relatively high disutility of work, and a work requirement therefore makes claiming unemployment benefits a less attractive option for them.

A key notion in our analysis is that ALMP may play a similar screening role as workfare. The potential similarity between workfare and ALMP has also been noted in Fredriksson and Holmlund (2006b). We take on board the idea in Kreiner and Tranaes (2005) that workfare/ALMP may be able to screen between individuals who are voluntarily and involuntarily unemployed. However, their framework is not directly applicable in our setting: We are interested in transitions into employment. In Kreiner and Tranaes' model, screening works through deterring non-workers from claiming unemployment benefits (pushing them onto minimum income support that is available without a work requirement), but it does not directly affect employment rates. We would like to capture the idea that voluntarily unemployed individuals would be able to find work if they wanted to (even in the absence of an activation program), but do not do so if benefits are too high or easy to obtain.

To be more precise, what we mean by screening in this context is the following: Workers differ in their job arrival rates, i.e. returns to search. For simplicity, we assume that there are two types of workers, low and high types. Neither job arrival rates nor search effort are observable to the policy-maker, so policy cannot be conditioned on them. We examine below whether the threat of an activation policy increases the marginal return to search more for the high type (with a high job arrival rate) than the low type. If the two types respond differently to the policy, it becomes easier for the policy-maker to separate between the types: the threat of activation increases the incentives to search more for the high type with good labor market prospects, and thus works toward higher increases in exit rates from unemployment by the high type, already prior to the actual activation phase. In this case the policy helps to deter in particular the high type from unemployment. ${ }^{3}$ While it appears plausible that it would be a good idea also in practice to induce those with higher returns to search to exert more search 
effort (the model features no differences in search costs), a caveat is that we do not provide an explicit analysis of the welfare properties of the program. Nevertheless, it is clear that the possibility to use activation as an (optimal) screening device hinges on whether the policy is able to separate different types of individuals. We provide a theoretical illustration and empirical evidence of such heterogeneous responses. ${ }^{4}$

To illustrate this idea in a simple setting, we extend the work by Andersen and Svarer (2014), who study the role of workfare in a conventional search-theoretic model with moral hazard, to a situation where workers are heterogeneous. Andersen and Svarer consider a model where the unemployed face a certain probability of being required to participate in a workfare program. This probability is denoted by $p_{a u}$. We analyze how different types of jobseekers react to changes in the activation intensity $\left(l_{a}\right)$, that is, the time they are required to participate in activation (conditional on being assigned to a program). In this model, activation is assumed to be useless per se, i.e. it does not affect workers' productivities or job arrival rates. This assumption is also common in other related literature, and we adopt it in our main analysis, but we also comment below on a case where activation may have a beneficial effect on job arrival rates.

Workers' instantaneous utility, $h$, depends on consumption (=disposable income), $(1-\tau) w$, where $\tau$ is the tax rate and $w$ is income when employed, and on leisure. The utility for the individual when at work is then $h\left((1-\tau) w, 1-l_{e}\right)$, where $l_{e}$ depicts working hours. When unemployed, utility is $h\left((1-\tau) b, 1-s_{u}\right)$, with $s_{u}$ denoting search intensity and $b$ denotes income when unemployed. The utility when the individual is required to participate in workfare is $h\left((1-\tau) b, 1-s_{a}-l_{a}\right)$. Income $b$ is assumed to be the same for the unemployed irrespective or their activation status.

The value functions (with $\rho$ denoting the interest rate) are 


$$
\begin{aligned}
& \rho V^{E}=h\left((1-\tau) w, 1-l_{e}\right)+p_{u e}\left[V^{U}-V^{E}\right], \\
& \rho V^{U}=h\left((1-\tau) b, 1-s_{u}\right)+\alpha^{i} s_{u}\left[V^{E}-V^{U}\right]+p_{a u}\left[V^{A}-V^{U}\right], \\
& \rho V^{A}=h\left((1-\tau) b, 1-s_{a}-l_{a}\right)+\alpha^{i} s_{a}\left[V^{E}-V^{A}\right] .
\end{aligned}
$$

In the above expressions, $\alpha^{i} s_{u}$ and $\alpha^{i} s_{a}$ are the probabilities of getting a job for the unemployed of type $i$ with or without workfare, respectively. The probability of losing a job is $p_{u e}$. The job arrival rate conditional on search effort for individual $i$ is denoted by $\alpha^{i}$ (whose value will be varied below). We assume that there are two groups of individuals, who differ in their job-finding rate, such that $\alpha^{2}>\alpha^{1}$ The groups are large in the sense that $\alpha^{i}$ is taken as given by each individual, i.e. it is a macro variable that is determined in the model. The differences in job-finding probabilities may reflect differences in skills or personality traits across the groups. Of course, if the labor market were perfectly competitive, such differences should be reflected in wage levels. On the other hand, in reality there may be reasons why an employer may not be able to tailor wage offers fully to the personal characteristics of job candidates, which would show up as differences in the likelihood of receiving job offers. ${ }^{5}$

How does search effort for the unemployed change when activation intensity $\left(l_{a}\right)$ increases? And how does the change depend on the job-finding rate - i.e. does more intense activation increase the benefits of search more for the high type (type 2)?

Denote the marginal benefit of search while in open unemployment by $B^{U}=\alpha^{i}\left[V^{E}-\right.$ $\left.V^{U}\right]$. It is shown in Appendix A that $\frac{\partial B^{U}}{\partial l_{a}}>0$. That is, as one would expect, the marginal benefit of search is increasing with the intensity of activation. The cross-partial derivative $\frac{\partial B^{U}}{\partial l_{a} \partial \alpha^{i}}$, which indicates how the impact of activation on the marginal benefit of search differs between types, has an ambiguous sign: on one hand, increasing the intensity of activation increases the benefits of search more for the high type, because their returns to search are 
greater (a direct impact from greater $\alpha^{i}$ ). On the other hand, the impact of more intense activation on their utility is less negative since they exit activation faster; this has an indirect negative effect on the benefits of search. It is therefore ultimately an empirical question how activation influences different types of individuals. If the direct effect dominates, an increase in the activation intensity raises the benefit of search more for the high type.

Note that we have assumed that the two types do not differ in their valuation of leisure (i.e. the function $h$ is the same for both types). Therefore, the mechanism at play in our setting is different to that in Kreiner and Tranaes, who have examined the screening role of workfare when agents differ in their valuation of leisure. In our setting, screening can arise in the labor market context even with identical preferences for leisure.

Turning to effects that occur during the activation phase itself and denoting the marginal benefits of search in the activation phase by $B^{A}$, we show in Appendix A that $\frac{\partial B^{A}}{\partial l_{a}}>0$. More intensive activation increases the benefits of search also during the activation phase. The sign of $\frac{\partial B^{A}}{\partial l_{a} \partial \alpha^{i}}$ is ambiguous. Here we have assumed that activation is unproductive in the sense that it has no direct effect on the job arrival rate. This assumption is in line with earlier literature, which has concentrated on examining the conditions under which unproductive workfare is desirable. If on the other hand we allowed for the quite realistic possibility that activation could increase the job arrival rate, and more so for the low type, then it would be more likely that activation would increase the benefit of search more for the low type. To keep the model tractable, we have not analyzed this case formally.

In this setting, active labor market policies may then work through two channels: (i) the threat of activation works towards deterring from unemployment especially those individuals who would be able to find work on their own but do not do so e.g. because benefits are too generous or easy to obtain (type 2) - this is the screening effect; and (ii) participation in activation itself also increases job-finding rates - call this the activation effect ${ }^{6}$. If workfare is 
productive in the sense that it increases job-finding rates, and more so for individuals who are less likely to find work on their own (type 1), participation in activation may help especially these types of individuals to find a job. If both screening and activation effects are at work, we would expect to observe a certain type of pattern in exit from unemployment: Type 2 individuals would exit unemployment predominantly before actual activation starts, i.e. we would observe a threat effect for type 2 individuals. ${ }^{7}$ Type 1 individuals, on the other hand, would enter the activation phase, and may find employment as a result. We aim to analyze whether such patterns are present in our data. In the empirical application, in line with the above framework, we use the predicted probability of finding work (in the absence of activation) as a measure to distinguish between type 1 and 2 individuals: if the person remains unemployed despite a high predicted probability (based on observable characteristics) of finding work, unemployment is more likely to be voluntary.

\section{B. Previous Empirical Literature}

Related to our focus on the screening role of workfare/ALMP, Fredriksson and Holmlund (2006) note that empirical evidence of the effects of workfare is limited, with papers on the threat effect of ALMP providing the most closely related evidence. A number of studies have documented the presence of a threat effect in the context of activation programs. For instance, Black et al. (2003) find that unemployed workers react to the notification of an activation requirement in a US-based study. Threat effects have been detected in the Swedish context by Hägglund (2011), who studies a pilot program in three municipalities, and by Carling and Larsson (2005) and Forslund and Skans (2006), who study an earlier youth activation program. Using Danish data, Rosholm and Svarer (2008) find that individuals react to a perceived risk of future program participation. Geerdsen (2006) finds that the exit rate from unemployment increases as individuals approach compulsory program participation, while Graversen and Larsen (2013) analyze the same program and argue that the previous estimates 
were upwards-biased. Maibom, Rosholm, and Svarer (2017) examine the impacts of three randomized field experiments aimed at newly unemployed workers in Denmark. They find that early interventions lead to positive employment impacts. Interestingly, the threat effect appears to be present only when the labor market conditions are good. On the other hand, no threat effect was found for long-term unemployed persons in Finland (Tuomala 2011).

However as argued above, to provide evidence of screening, we should find a pattern where the threat effect is heterogeneous such that individuals with good labor market prospects react to the threat of activation. While a few earlier papers have studied some aspects of heterogeneity in the responses to threats of activation ${ }^{8}$, ours is the first study to investigate differences in reactions to the threat of activation in a systematic, theory-driven way. We use the predicted probability of finding work (in the absence of activation) as a proxy for an individual's labor market prospects and analyze whether the pattern of exit (both regarding the timing and heterogeneity across individuals) from unemployment after the introduction of activation supports the idea that there may be a screening role for ALMP.

Let us next turn to papers that have examined whether activation programs have different impacts among disadvantaged youth (mostly proxied by having low education). Caliendo, Kunn, and Schmidl (2011) evaluate a number of programs in Germany and find persistently positive employment effects that are stronger for those with better education. Maibom, Rosholm, and Svarer (2014) evaluate a randomized field experiment conducted in Denmark. The treated job seekers received more intensive support from caseworkers and mentors, and this was combined with other policies. They find that the treatment effect varies depending on the individual's education level, with no impact for those with basic education only. Finally, Hämäläinen, Hämäläinen, and Tuomala (2014) provide an impact evaluation of a Finnish activation program similar to the Swedish one that we analyze, also targeted at youth. They 
find that the policy had positive but modest employment effects, and the effects are again concentrated to those with better education. ${ }^{9}$

A large meta-analysis of active labor market policies by Card, Kluve, and Weber (2018) finds that these policies are on average less effective among youth, but there is some evidence suggesting that disadvantaged groups in general may benefit more than average participants. Another meta-analysis, by Kluve et al. (2019), concentrates on ALMP targeted at young unemployed persons. They find that programs that contain multiple services and those that conduct profiling of job applicants lead to better outcomes. They also find some evidence that programs focusing on disadvantaged youth lead to greater employment gains.

As elaborated in the Introduction, we contribute to the literature by providing evidence of the screening role of labor market programs and by analyzing whether the program studied is effective in helping disadvantaged youth, using exceptionally rich data on individual background characteristics that may be related to one's position in the labor market. We do so in the context of a nationwide major activation program.

\section{The Youth Activation Program}

The activation program we study is the Youth Job Guarantee (YJG) that started in Sweden in December 2007. The program involves activation that starts 90 days after a person has registered as an unemployed jobseeker at the Public Employment Service, and it involves all unemployed individuals who are under 25 years of age. That is, all individuals who have not yet turned 25 should be assigned to the program after 90 days of unemployment. ${ }^{10}$ The activation is mandatory for those in the targeted age group, and a refusal to participate could incur sanctions in the form of withdrawn unemployment benefits. If assigned to the program, the individual needs to participate until he/she finds a job or enrolls in education, i.e. individuals who are already in the program are not allowed to drop out when they turn $25 .^{11}$ 
Figure 1 illustrates the structure of the program. The first three months (90 days) of an unemployment spell consist of open unemployment. After 90 days, the employment office undertakes an in-depth assessment of the situation of the individuals in the target group. In the first phase of activation that starts after 90 days, the program mainly takes the form of job search assistance. After a further 90 days, the individuals who are still unemployed are transferred into a second phase of activation that, on top of job search activities, also can involve short periods of training or work placement to gain work experience. The motive behind the clear focus on job search assistance throughout the program is to avoid the kind of lock-in effects that were shown to occur in previous youth programs (Government Bill 2009/10:1). ${ }^{12}$ The content of the program is relatively flexible and should be tailored according to individual needs.

The activities within the YJG program are supposed to imply full-time participation. However, based on a survey among participants in 2009, Martinsson and Sibbmark (2014) conclude that this ambition is rarely met in practice. On average the participants reported that they spent 14 hours per week applying for jobs and participating in activities.

For some (well-defined) groups of unemployed persons, program participation also affects the time-profile of the replacement rate of unemployment insurance (UI): During the period we study, the earnings-related UI benefits were normally equal to $80 \%$ of prior earnings (up to a cap) for the first 200 days of unemployment and declined to $70 \%$ for the next 100 days. For some individuals participating in the YJG program, the rules were different: the $80 \%$ replacement rate applied only for the first 100 days of unemployment, declined to $70 \%$ for days 101-200 and further to $65 \%$ for days $201-300$. Therefore, for some individuals, the policy involves elements of both activation and financial incentives. However, the individual is unaffected by the faster reduction of benefits if she (i) has children; or (ii) is only eligible 
for the basic UI benefits; or (iii) has earnings-related benefits that would exceed the maximum amount of benefits (SEK 680 [EUR 68] per day).

Individuals who are not entitled to any UI benefits (because they do not fulfil the working condition ${ }^{13}$ ) receive a small monetary compensation if participating in the program (SEK 135 [EUR 13.5] per day for 2010).

\section{Data}

We combine data on individuals' employment status and labor market history with information on their education, (past) health and other relevant personal characteristics. The data on unemployment spells come from the register of the Public Employment Service (PES), and the data on health status from hospital and drug registers provided by the National Board of Health and Welfare. The latter include yearly individual-level information on all purchases of prescribed medicine, all inpatient medical contacts ${ }^{14}$ and all outpatient medical contacts in specialized care. ${ }^{15}$ To these registers we have also added a number of demographic variables as well as information on wages from Statistics Sweden, information on unemployment benefit uptake from the unemployment insurance funds, and information on sickness benefits as well as activity compensation (disability pension) ${ }^{16}$ uptake from the National Social Insurance Board. All data, except for the wage data, cover the entire Swedish population. The wage data are collected through an annual survey (in the fall), and cover the whole public sector, all large firms and a random sample of smaller firms (in total, about $50 \%$ of employees in the private sector are covered).

The YJG program was introduced in December 2007, and we analyze its effects in 2008 2010. ${ }^{17}$ Our 2008 sample includes all individuals aged 19-29 who became unemployed between October 2007 and September 2008, and therefore became eligible for the program between January 2008 and December 2008, if they were still unemployed and below 25 years 
of age at that time. The 2009 and 2010 samples are constructed in the same manner. All the analyses below are conducted using the combined 2008-10 data, and the data allow us to follow the individuals several years after the start of the unemployment spell.

In our baseline analysis, we define a person as having found a job if she becomes employed for at least 30 consecutive days. In the data, an unemployed person can become employed in two different ways: (i) A person is deactivated from the PES register, and the reason for leaving the register is (unsubsidized) employment. (The reason for leaving the register is recorded by the caseworker.) (ii) A person remains in the PES register, but is registered as a temporary, hourly or part-time employee. (A person can remain in the PES register if she has found employment but is still searching for other jobs.) In both cases we require the person to be employed for at least 30 consecutive days. In the first case, that means that the individual is not allowed to reappear in the register during the next 30 days. ${ }^{18}$

Table 1 provides descriptive statistics on the background characteristics of the individuals in the sample (excluding the health indicators). Column (1) includes all unemployed 19- to 29-year-old individuals; column (2) includes all participants in the YJG program; and columns (3) and (4) include unemployed persons within one year from the eligibility cut-off age, that is, 24- and 25-year-old individuals, respectively. The 25-year-olds have somewhat higher educational attainment and their previous earnings are higher than the earnings of the 24-year-olds, reflecting the fact that they are older. In our main analysis in Section V, we use an RD design, where the effects of the YJG program are identified from a discrete change in program eligibility and the probability of program assignment at the threshold of turning 25 . Therefore, what matters for our analysis is whether there are jumps in any of the background variables at the threshold. We examine this issue in Section V.D.

Table 2 provides descriptive statistics for the main health indicators used in the analysis. Column (1) now includes all other Swedish residents who are 24 or 25 years old but who have 
not been unemployed in our data (whereas the data in Table 1 come from the PES register and hence include only unemployed individuals). Unemployed individuals (columns (3) and (4)) appear to have worse health than other individuals of their age (column (1)), measured for example by past use of neurological drugs or drugs for mental illness. On the other hand, participants in the YJG program (those in column 2 appear on average to be healthier than the 24- and 25-year-olds in our sample; this is likely explained by the fact that the average individual in the YJG program is younger than those in columns (3) and (4). There are rather small differences between the individuals in columns (3) and (4).

Figure B.1 in Appendix B provides a first descriptive analysis related to observed unemployment duration in our data. The graph reveals that 24-year-olds (the target group of the program) exit unemployment faster before the 90-day threshold as well as right after, but the survival curves overlap for longer unemployment spells. The sample in this descriptive analysis is limited to individuals who are born during the same calendar year (to achieve better comparability between the groups). We next turn to an econometric analysis of the effects of the YJG program, both for all unemployed persons in the relevant age groups, as well as in subgroups defined by individual labor market prospects.

\section{Empirical Analysis}

\section{A. Empirical Strategy}

We use a regression discontinuity design to estimate the effects of the Youth Job Guarantee program, using the fact that only individuals under 25 years of age at 90 days of unemployment are eligible for the program. Even though age may affect re-employment probabilities, we can expect individuals close to the eligibility cut-off to be similar to each other in all other respects, except that individuals on one side of the cut-off receive the treatment (program eligibility) and individuals on the other side do not. (The balance of 
background characteristics at the threshold is examined in Section V.D.1.) Hence any differences in employment probability that we find between individuals on each side of the cut-off can be attributed to the YJG program.

An important point to note is that the assignment variable in our application is not age per se, but age at a particular date (90 days after entering unemployment). Once assigned to the program, individuals risk losing their unemployment benefits if they drop out when they turn 25. Hence, we avoid an often-encountered problem in age-based RD analysis, i.e. the possibility that reactions of individuals close to the cut-off age are affected by anticipation of future changes in treatment status when they cross the age threshold (Lee and Lemieux 2010). Further, unlike RD-type designs using age as the assignment variable, in our case program assignment is stochastic (as in regular RD): To the extent that one cannot fully control the date of becoming unemployed - in particular, whether the unemployment spell starts more or less than 90 days before one's $25^{\text {th }}$ birthday - then program assignment in our application is not deterministic.

However, a potential threat to a causal interpretation of our estimates is that the presence of the program could affect individuals' decision to register at the PES. If there are individuals with detailed knowledge of the program and the eligibility requirements before registering at the PES, even though they cannot fully control the time of becoming unemployed, some of them may choose to delay registration to avoid activation. ${ }^{19}$ This would lead to sorting around the eligibility threshold. ${ }^{20}$

Figure 2 shows the number of individuals entering unemployment, by age at day 90 after the start of the unemployment spell (where age is measured relative to the cut-off age of 25). There is no evidence of a decline in the number of individuals registering just before the eligibility cut-off or of a spike just after the cut-off. Hence, the figure does not suggest that individuals time their registration to avoid activation. This is also confirmed by the McCrary- 
test (McCrary 2008), which does not detect any discontinuity at the threshold. ${ }^{21}$ (Related to the subgroup analysis that we perform below, Figure C. 1 in the online appendix shows that there is no sorting for the different quartiles of predicted employment probabilities either.)

Finally, could identification be compromised by the existence of other programs? Sweden has a rich set of training and job search assistance programs also for unemployed individuals older than 25. However, as a result of the introduction of the YJG, program participation is much more common among unemployed individuals under 25 years of age; see Figure 3 . The figure shows that the likelihood of participating in some labor market program increases sharply for 24-year-olds around 90 days of unemployment, whereas there is no such pattern for 25-year-olds. This is reassuring: First, it indicates that we do not need to worry about possible confounding effects arising from program participation by older job-seekers. Second, the figure confirms that the difference in program participation between the age groups indeed occurs after 90 days of unemployment, which ensures that we can obtain estimates for the threat effect (i.e. any possible effects observed before 90 days are not due to program participation).

Turning to other age-based policies, differences in benefit or tax policies do not pose problems for our analysis. Individuals become eligible for basic unemployment benefits already when they turn 20, whereas earnings-related UI benefits have no age limit (but are instead based on UI fund membership status). On the tax side, a potentially relevant payroll tax cut was introduced in July 2007, where the reduction applied to individuals who had not yet turned 25 in the beginning of the year. Despite the apparent similarity to the YJG eligibility rule, we are confident that this policy does not pose any problem for our identification strategy: First, eligibility for the payroll tax cut is determined by year of birth, not by the individual's age at a particular date as for YJG eligibility (that is, day 90 of the unemployment spell). Therefore, the eligibility cut-offs of the two policies do not in general 
coincide. (One cannot determine a cut-off for the payroll tax cut in our RD figures, as the running variable for a corresponding analysis of the payroll tax cut would be different.) Second, eligibility for the payroll tax reduction runs out once the individual turns 25 , and therefore individuals close to the cut-off for the tax reduction are only eligible for a very small subsidy. For this reason, there is no meaningful discontinuity in the subsidy amount at the eligibility threshold. (As we noted above, the YJG is different in this respect: once an under25 -year old is assigned to the program, she remains assigned even after turning 25 . This is crucial for applying RD in this setting.) Third, the payroll tax cut came into force already in mid-2007. In Section V.D.2, however, we show that there is no placebo effect of the YJG in 2007 (cf. Figure 9). This provides further support to the argument that our results are not affected by the payroll tax cut.

In sum, other activation programs or age-based tax and benefit policies do not compromise our analysis. The only potential confounding policy is the New Start Jobs program, which constituts subsidized employment targeted at certain subgroups of the unemployed persons. We examine this policy closely in Section V.D.5.

\section{B. Results for the Whole Sample}

We first present a graphical analysis of our data, with the purpose of analyzing whether there are any jumps in the job-finding probability at the YJG eligibility threshold (i.e. between 24and 25-year-olds). We use four dummy variables to measure the effect on employment: These indicate whether the individual becomes employed during the first 90, 180, 270 and 365 days after entering unemployment. Hence, the first outcome $\left(D_{90}\right)$ measures the threat effect, while the other outcomes $\left(D_{180}, D_{270}\right.$ and $\left.D_{365}\right)$ capture the total effect of program eligibility after different lengths of time. ${ }^{22}$ It should be noted that the latter three outcomes capture a combination of the threat effect and possible program effects. The causal effect of the program itself (say the probability of finding work between days $90-180$ of the 
unemployment spell, while the individual already participates in activation) cannot be estimated without stronger assumptions, as the individuals who remain unemployed at day 90 are no longer representative of the overall pool of unemployed persons.

The threat effect (or pre-program effect) is analyzed in Figure 4a. In the figure, the individuals in the data are arranged according to their age at day 90 after entering unemployment, and age is measured relative to the cut-off age of 25 . That is, the negative portion of the $\mathrm{x}$-axis in Figure $4 \mathrm{a}$ consists of individuals who would become eligible for the YJG if they remain unemployed for 90 days. Individuals are divided into bins of one month, and we plot bin averages of the $D_{90}$-dummy. As our age variable is continuous - it is measured in days - a full-fledged RD analysis is possible. We fit local linear regressions of $D_{90}$ on relative age using a triangle kernel and an optimal bandwidth (as defined by Imbens and Kalyanaraman 2012). ${ }^{23}$ Bins with $x<-3$ and $x>3$ are excluded from the figure for clarity, as we want to focus on individuals close to the eligibility cut-off. The solid line in the figure shows the fitted values from these regressions, and the dashed lines show the associated $95 \%$ confidence intervals.

Figure $4 \mathrm{a}$ indicates that there is a significant threat effect, even though it appears to be quite small: being eligible for the YJG program (i.e. being under 25 years of age at 90 days of unemployment) increases the probability of finding employment during the first 90 days after entering unemployment by less than 2 percentage points. Taking into account that about $30 \%$ of the 25-year-olds find employment within 90 days, this would correspond to an increase of about $6 \%$.

Figures $4 \mathrm{~b}-\mathrm{d}$ present similar analyses of the effect at day 180, 270 and 365 after the onset of unemployment. That is, we look at the relationship between age and the $D_{180^{-}}, D_{270^{-}}$and

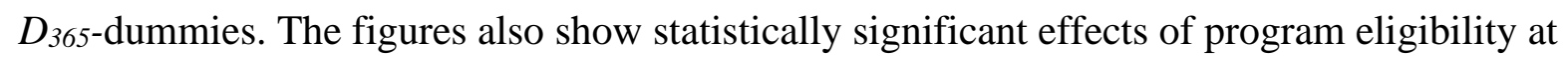


day 180 , but not at day 270 or 365 . Hence, the figures suggest that job-finding among those ineligible for the YJG program starts to catch up later on during the unemployment period.

We next report RD-estimates of the effect of being eligible for the YJG program in Table 3. The estimates confirm the findings from the graphical analysis: The threat effect for the whole sample is approximately 1.7 percentage points, which corresponds to an increase of around $6 \%$ if we relate it to the average outcome among 25 -year-olds. (The effects reported in Table 3 are positive, as the observed drop in the employment probability at the threshold of turning 25 (Fig. 2) corresponds to a positive effect. That is, younger individuals - those who are eligible for the program - have a higher probability of finding work.)

The employment probability remains marginally higher among those who are eligible for the YJG program also at day 180 after registration at the PES. After that, the effects are no longer statistically significant. Given that the effect by day 180 (and later) is smaller than the threat effect, the results indicate that participation in the activation measures by itself does not significantly affect employment probabilities. The overall effects of the program can therefore largely be attributed to the threat effect.

How do our results compare with earlier estimates of the magnitude of threat effects? Due to differences in program details, empirical methods and the way results are reported, the comparison is not straightforward. For example, Black et al. (2003) find that the program they study shortened the unemployment spell by two weeks. The corresponding estimate in Rosholm and Svarer is two and a half weeks. Papers that report time-specific hazards find large short-term increases in employment hazards (e.g. Hägglund 2011). The most closely linked papers to ours are perhaps those studying an earlier Swedish program targeted at youth. Carling and Larsson (2005) find that the threat effect amounts to a $10 \%$ increase in the jobfinding rate, but that the impact quickly vanishes and reaches zero by 120 days. Forslund and Nordström Skans (2006) find that the probability of still being registered at the PES declined 
by $4 \%$ during the first 90 days of unemployment. Our result - an approximately $6 \%$ increase in the job-finding rate due to being eligible for the treatment - is well in line with these earlier studies. Compared with the results from two meta analyses, the immediate impact in our study $(6 \%)$ is larger than the average short-run impact (precision-weighted mean equal to approximately 3\%) found in Card, Kluve, and Weber (2018) but on the other hand they find the longer-run impacts to be greater than the impacts in the short run. The mean impact on employment probability, as reported in Kluve et al. (2019), is also 6\%.

When discussing the magnitude of the effects, however, it should be noted that the effects that we have reported are intention-to-treat effects, i.e. effects of program eligibility. When interpreting the results, one must bear in mind that program take-up is incomplete. The relationship between age (at 90 days of unemployment) and participation in the YJG program is depicted in Figure 5. The figure is drawn in a similar way as Figures 4a-d, but the dependent variable is now a dummy for actual participation in the YJG program. The bandwidth chosen is the same as in the estimation for the $D_{180}$ dependent variable. The figure is drawn only for the relevant subpopulation, i.e. individuals whose unemployment spell lasted over 90 days.

Figure 5 reveals an interesting pattern. Take-up is practically zero for individuals over 25 years of age, as it should be. For most age groups below 25, take-up is around 50 percent, but it falls sharply before the 25 -year threshold. The likely reason for this is that caseworkers have not been able to assign individuals to the program straight away at 90 days of unemployment; rather, assignment takes some time (e.g. due to the high workload on caseworkers), and the individual's age is checked only at the time when program assignment is considered. Some people who are close to 25 at day 90 have therefore turned 25 by that time and are no longer eligible. There is nevertheless a statistically significant drop in take-up at the threshold of around 30 percentage points. 
The effects that we report above in Table 3 correspond to a sharp RD design, and should be thought of as intention-to-treat effects - they are the effects of program eligibility. On the other hand, Figure 5 clearly shows that program assignment was very fuzzy. Using a fuzzy RD design, we get an estimate of, e.g., the threat effect of 0.089 (standard error 0.0183), i.e. an approximately 9 percentage point (or 30\%) increase in the probability of finding work during the first 90 days after entering unemployment. Naturally, this effect is considerably higher than the sharp RD estimate, since it is essentially a Wald/IV-estimate that involves dividing the sharp RD estimate by the estimated jump in take-up at the threshold.

When take-up is incomplete, one would usually consider the fuzzy estimates to be preferable, as they take into account the fact that not everyone who is eligible actually receives the treatment. In our context, the fuzzy estimates are somewhat hard to interpret: how should one think of the threat effect on the "compliers", as the threat effect is about what happens before people actually enter the program and before the question of compliance becomes relevant. On the other hand, if the low actual take-up affects the strength of the threat (if people know that the program is not strictly enforced), the fuzzy estimate would take this into account. Nevertheless, since the sharp RD estimates are more conservative and more straightforward to interpret in our context, we focus on them in the following analyses.

\section{Results by Subgroups}

We next turn to analyze how the effects of program eligibility differ by individual background. From the point of view of our motivating idea - whether the program functions as a screening device and/or whether it helps disadvantaged individuals with a weak labor market position - we need a measure of an individual's labor market prospects overall (not yet thinking about any program effects). To achieve this, we first analyze how the individual background characteristics found in our data are related to the probability of finding employment during the first year of the unemployment spell before the YJG program was in 
place. To create a summary measure of an individual's labor market position, we then use the results from this estimation to predict employment probabilities for the individuals in our sample. Next, we divide the sample, by year, into quartiles by the predicted probabilities: those in the $1^{\text {st }}$ quartile have the worst employment prospects, whereas those in the $4^{\text {th }}$ quartile are most likely to find work (based on observable characteristics). Given that many characteristics (beyond, say, education) are found to be related to labor market prospects, this procedure has clear advantages over concentrating on any single variable as a proxy for disadvantageousness. This approach is particularly attractive as it allows us to take full advantage of the richness of our data.

Using a prediction model to classify individuals according to their labor market prospects is not uncommon in the program evaluation literature; recent examples include Altmann et al. (2016) and Nekoei and Weber (2017). It is important to note that we estimate the prediction model on out-of-sample data (i.e. pre-reform data from 2007), and we therefore avoid any biases that might arise from endogenous stratification (Abadie, Chingos, and West 2016). ${ }^{24}$

The empirical specification for the prediction exercise follows that of Nekoei and Weber (2017), who use a non-parametric model of background characteristics to predict nonemployment duration. We use data on unemployed individuals in 2007, and control for the individual's labor market history and (lagged) income in a non-parametric way (using splines of lagged income and the number of days in previous unemployment spells), and further include various other controls that appear to matter for one's labor market prospects. The results are presented in Table 4.

Several groups stand out: Individuals with compulsory education only (or missing information on education) and those born outside the Nordic countries appear to have a clearly lower probability of finding a job than others. Registered disability, having received social assistance and having children is also strongly negatively correlated with job-finding. 
Regarding the health variables, individuals who received disability pension, who were treated for mental illness (including both inpatient and outpatient care) or took a neurological drug have particularly low job-finding rates. As explained above, we then use the model to predict employment probabilities for the individuals in our main sample (2008-2010) and divide the individuals into quartiles by their predicted employment probabilities. Descriptive statistics for the different quartiles serve to make the differences between them more explicit (see Table B1 in the appendix). For example, there is a clear concentration of mental health problems in the $1^{\text {st }}$ quartile: e.g. it is 12 times more common for individuals in the $1^{\text {st }}$ quartile to have been treated for mental illness in the past year compared to individuals in the $4^{\text {th }}$ quartile. It is also much more common for individuals in the $1^{\text {st }}$ quartile to have a registered disability and to have received disability pension. Therefore, even though characteristics such as low education and immigrant status are very important for labor market prospects, our data clearly indicate that other factors such as past mental health problems are also crucial in this respect.

We next estimate the effect of program eligibility by quartiles of the predicted employment probabilities. The results are shown in Figures 6 and 7 (for the threat effect and the effect until day 180 , respectively) and in Table 5.

We find no evidence that individuals in the most disadvantaged labor market position are affected by the threat of activation: The estimated threat effect is close to zero and statistically insignificant for the lowest quartile, while it is significant at the 10 percent level for the second quartile and strongly significant for the top quartiles. These results are thus consistent with the idea that individuals in a better labor market position may be more likely to respond to the threat of activation, and hence with the notion that activation programs may work as a screening device. If we relate the estimated effects for quartiles 2-4 to the mean outcome among 25-year-olds, they correspond to an increase in the probability of finding employment during the first 90 days of 5-6 percent. ${ }^{25}$ 
The effect of program eligibility remains statistically significant at the 10 percent level for quartile 3 also at 180 days after entering unemployment. For the other quartiles there are no longer any statistically significant differences between the eligible and ineligible in terms of transitions to employment. At later follow-up times, i.e. at day 270 and 365 after the onset of unemployment, all estimates are insignificant (not shown). Hence, while program eligibility seems to have shortened unemployment spells for some of the unemployed individuals - in particular those with a more advantaged labor market position - we find no long-term effects on employment for any of the groups. The results also indicate that the effects for quartiles 24 are driven by the threat of program participation, as entering the activation phase itself does not appear to strengthen the estimated effects for these groups. The results do not provide any support for the idea that the benefits of activation are concentrated among those most in need of assistance.

Finally, as explained at the end of Section V.B, we focus on intention to treat effects from a sharp RD design (rather than Wald estimates from a fuzzy RD design), because the distinction between compliers vs. non-compliers is somewhat hard to interpret in the context of the threat effect. It is nevertheless important to check that there is a significant jump in take-up at the age eligibility threshold in each quartile. Figure B.2 in the appendix confirms that this is the case. The jump is somewhat larger for the top quartiles but is still above 20 percentage points for the lowest quartile. The simple fact that these individuals have registered at the PES implies that they should be willing and able to work, despite some individuals being in a more challenging position than others. The official rules for program participation are similar regardless of individual background characteristics, and possible differences in subsequent program assignment or take-up probabilities are likely to be hard for the individuals to predict a priori. 


\section{Validity and Robustness Checks}

We now turn to assess the validity of our RD design. Since some of our main conclusions stem from the analysis of how the treatment effect varies by quartiles of predicted employment probabilities, we perform robustness checks both based on the entire sample and separately by quartiles. We discuss all the robustness checks below, but for the sake of space, we report the detailed results by subgroup in a separate online appendix; see Appendix C.

\section{Balance of Background Variables and Robustness to Covariates}

First, we check whether there are any discontinuities in any pre-determined variables at the eligibility cut-off. When examining the balance of background variables at the threshold, we look at the following variables: gender, birthplace (dummy for being born outside the Nordic countries and dummy for being born in another Nordic country (not Sweden)), having a registered disability, level of education (three dummies), being married, employment status in the previous year, income from work in the previous year, receipt of unemployment insurance in the previous year, receipt of social assistance in the previous year, being a parent in 2007, and the month of entry into unemployment. We also include health-related variables as well as variables with information on the individuals' unemployment history.

We draw figures similar to Figure 4 for all the background variables and run separate RD analyses - identical to those that we conducted for the outcomes of interest - for each background variable to estimate the magnitude of any possible jumps at the threshold. The results are depicted in Figure 8. To keep the dimensions of the figure manageable, we exclude dummies for the month of entry into unemployment, even though we run balance checks for those too, since the time of entry may influence employment prospects. In total, we run balance checks for 38 background variables. Most of them are balanced at the threshold. Small but statistically significant jumps are found for the month of entry into unemployment (August, coefficient 0.00633 , standard error 0.00242; November -0.00388 , s.e. 0.00187 ; and 
December -0.00513, s.e. 0 .00234), as well as two other variables (receipt of UI benefit, 0.0118 , s.e. 0.0058 ; and the number of previous programs -0.047 , s.e. 0.234 ), while one variable has a jump that is marginally significant (receipt of social assistance, 0.0092, s.e. $0.0049)$.

Given that we have many background variables, some statistically significant jumps are of course expected. The discontinuities that we observe do not seem to follow any clear pattern (e.g. they do not indicate that individuals with background characteristics associated with good employment prospects would be concentrated on the left-hand-side of the threshold). To further ensure that our results are not driven by any kind of selection of individuals at the threshold, we check the robustness of our results to including controls for background characteristics. In addition to the variables included in Figure 8 and dummies for month of entry into unemployment, the regressions also control for municipality fixed effects. Our results are robust to controlling for background characteristics: The estimates for the threat effect and the effect at day 180 remain highly significant and the point estimates stay very similar; see Table 6.

We have also checked the balance of the background variables and the robustness to adding covariates for the estimations by quartiles; see Figures C.2-C.5 and Table C.1 in the online appendix. ${ }^{26}$ As in the main analysis, there are some statistically significant jumps for some of the background variables. Again, the discontinuities seem quite random and do not appear to have any meaningful pattern. It is also reassuring that the treatment impact and the pattern of reactions across the quartiles remain qualitatively the same when adding covariates.

\section{Placebo Tests}

As a further robustness check, we carry out several placebo tests. First, our data allow us to examine the presence of pseudo-effects before the YJG program was in place. However, individuals who became unemployed before the end of 2006 may still have been affected by 
the previous youth program ${ }^{27}$, and towards the end of 2007 individuals may start to anticipate that if they stay unemployed long enough, they will eventually become eligible for the YJG program (from December 2007 onwards). For this reason, we limit this placebo check to examining the presence of a threat effect among those who became unemployed during January-June 2007. (Ending the sampling in June is a cautious yet somewhat ad hoc choice, since it is not clear when the first anticipation effects might occur, if there are any. The program was first suggested already in April 2007 and the government bill was submitted in May, but on the other hand unemployed youth might not be very well informed about such policy plans. The results are not affected if we consider unemployment spells that started e.g. in January-August 2007 instead.) Figure 9 shows that there is no discontinuity at the threshold for this sample.

We also examined whether there are placebo effects at the threshold between 23- and 24year-olds (where age is again measured at day 90 of the unemployment spell, with this placebo threshold corresponding to -1 on the $\mathrm{x}$-axis in Figure 4), as well as the threshold between 25 - and 26-year-olds ( +1 on the $\mathrm{x}$-axis in Figure 4). There are no labor market programs or other relevant policies that would be expected to cause a discontinuity in the probability of finding work at these thresholds. Indeed, all the estimated effects are close to zero at both thresholds; see Table 7.

The same placebo tests were performed for the estimations by quartiles (see Figure C.14 and Tables C.2-C. 3 in the online appendix). The results from the placebo tests in 2007 by quartiles do not give rise to any concerns. Most of the placebos by quartiles for the thresholds of turning 24 and 26 are also not statistically significant, but there are some negative impacts of turning 24 (for quartile 1) and turning 26 (for quartile 2). However, as the corresponding estimated treatment impact in the main analysis is positive, these observations work against detecting a significant treatment impact. 


\section{Robustness to Bandwidth Selection}

Figures 10 and 11 plot the estimated effects (and the 95\% confidence intervals) from the sharp RD design (the effects of program eligibility) as a function of bandwidth. The figures show that our results are robust to bandwidth selection. The threat effect and the effect during days 1-180 become insignificant only at bandwidths far below the optimal bandwidth. ${ }^{28}$ In online Appendix $\mathrm{C}$ we show figures similar to Figures 10 and 11 for the different quartiles of predicted employment probabilities; see Figures C.6-C.13. In particular, the estimates for the second quartile turn out to be somewhat sensitive to bandwidth selection, while the estimates for quartile 3 and 4 are fairly stable. All in all, the result that the very weakest individuals those in the lowest quartile - do not respond to the threat of activation is very robust, while some individuals with better labor market prospects do.

\section{Calonico, Cattaneo, and Titunik (2014) Robust Inference}

Calonico, Cattaneo, and Titunik (2014) recognize that since implementing an RD design in practice normally requires using observations that are away from the cut-off value of the assignment variable, ignoring the resulting bias leads to biased confidence intervals for the estimated effects. We examined the robustness of our results to using the robust inference procedure suggested by Calonico, Cattaneo, and Titunik (2014). The results are reported in Table 8.

The robust confidence intervals are naturally somewhat wider than their conventional counterparts, but the threat effect and the effect by day 180 remain highly significant. A similar analysis for the subgroups is presented in online Appendix C, Table C.4. The threat effect remains significant at the $5 \%$ level for quartile 4 and at the $10 \%$ level for quartile 3 . The effect by day 180 is significant at the $10 \%$ level for the fourth quartile but turns insignificant for quartile 3 . 


\section{Robustness to Changes in the Definition of Employment}

So far, we have assumed that a person has found a job if she has left the PES register due to unsubsidized employment or has been registered as a temporary, hourly or part-time employee for at least 30 consecutive days. To check whether our results are sensitive to how we define employment, we also estimate our model with two alternative definitions. Col. (2) in Table 9 shows the results for a stricter definition of employment, where we require employment spells (incl. spells with temporary, hourly or part-time work) to last for at least 60 days to be considered employment. The estimates remain almost identical. This is also the case for the estimates by quartile; see Table $\mathrm{C} 5$ in the online appendix.

Second, not considering subsidized employment as employment is a conservative choice that could potentially lead us to underestimate the effects of the YJG program. In 2008 the rules for eligibility for one type of subsidized employment, New Start Jobs, differed for individuals who had/had not turned 25 (thus, the same age cut-off as for the YJG): Employers could receive this subsidy if hiring a person who had been on disability pension benefits, sick leave, or unemployed for at least 6 months if this person had not yet turned 25. Individuals who had turned 25 had to be on disability benefits, sick leave or unemployed for at least 12 months before employers would be entitled to the subsidy. Therefore, the 24 -year-olds in our sample may become eligible for this type of subsidized employment earlier on in the unemployment spell than their 25-year-old counterparts, in particular if they have been on disability benefits or on sick leave prior to unemployment. (From March 2009, the rules were changed to be the same for 24- and 25-year-olds.) By disregarding all hires where the New Start Job subsidy was paid out we thus risk underestimating the effects of the YJG program, while we risk overestimating the effects if we treat these jobs as regular employment. 
However, as we show in col. (3) in Table 9, our estimates are very similar if we instead treat New Start Jobs as regular employment. This is also the case for the estimates by quartiles; see Table C.5 in the online appendix.

\section{Impacts on the Quality of the Job Match}

Overly stringent conditionality can imply that as job seekers have more limited time for job search, the quality of the job match may deteriorate. To investigate if faster transition to employment comes at the expense of worse match quality, we use total earnings (or log earnings) during the subsequent two years as well as the monthly wage, which is measured in the fall the year after the unemployment spell starts, as outcomes. ${ }^{29}$ These measures are among those commonly used to gauge impacts on match quality in the previous literature (e.g. van den Berg and Vikström 2014). The estimates, reported in Table 10, are statistically insignificant and economically small, suggesting that speedier job-finding did not affect the quality of job matches. We do not find any significant impacts on job quality for the different quartiles either (these results are not reported).

\section{Accounting for Changes in Financial Incentives}

For an overwhelming majority of the treated individuals (89\%), the program involved participation in activation policies only. However, as we noted in Section III, a proportion of the treated individuals were not only subject to activation policies, but also experienced changes in their financial incentives. Those unemployed persons who had children, who received the basic level of benefits only, or whose earnings-related benefit exceeded a cap level were excluded from being subject to changes in financial incentives. Given that the groups whose financial incentives changed are well-defined, we can examine the effects of program eligibility separately for groups whose financial incentives changed vs. those whose did not. 
Table 11 shows that the average effects (both before entering the program and afterwards) are positive both for those who faced a cut in benefits and for those who did not: hence activation has an effect on job-finding rates even in the absence of any explicit financial incentives.

From these numbers we cannot derive causal estimates of the effects of financial incentives (compared to pure activation) on the probability of finding work: the groups whose financial incentives changed may also react to activation in a different way than others. Nevertheless, it is useful to check that the program also has an impact for the subgroup without changes in financial incentives.

We cannot carry out an analysis analogous to that in Table 11 for the quartiles, as the sample of individuals who faced a benefit cut becomes too small for an RD analysis when divided into quartiles. Despite being unable to carry out a comparison, we can estimate the effects separately for the group whose financial incentives were not affected. The main pattern that we find is unaffected: the threat effect is insignificant for the first quartile and positive and statistically significant for quartiles 3 and 4 - see Table C.6 in the online appendix. Alternatively, we can run the RD analysis while controlling for a dummy indicating whether an individual belonged to those population groups that were subject to the cut in benefits (if they were eligible for the program). This allows for higher job-finding rates for individuals who faced a cut in benefits, as well as different effects of financial incentives in each quartile (as we are carrying out the analysis separately for each quartile). All our results remain intact if we control for the effect of financial incentives in this way, as shown in Table C.7 in the online appendix. 


\section{Impact on the Government Budget}

To assess the impact of the YJG policy on the government budget, we contrast the program costs with the gains from higher job-finding rates. In doing so, we think of YJG as an additional ALMP offered to unemployed individuals below age 25, on top of what is offered to slightly older individuals. The government budget will be affected by the cost of running the program, as well as higher tax revenue and reduced income transfers since individuals leave unemployment faster. ${ }^{30}$

Tax revenue from increased employment: Our results show that eligibility for the YJG induced 24-year-olds to find employment somewhat faster with no impact on wages. To assess the program's impact on taxes paid and benefits received, we require an estimate of the impact of the program on average duration in unemployment. To arrive at such an estimate, we first estimate the effect of program eligibility on the probability of having found a job at each point in time after the start of the unemployment spell. Plotting the estimates and calculating the area underneath the curve provides an estimate of the effect of the program on average unemployment duration. ${ }^{31}$ In practice, we use a stepwise linear function and assume that the effect is constant within each 10-day-interval. The results are depicted in Figure 12. The figure shows that exit rates from unemployment into employment start to increase before individuals become eligible for the program. The difference in the probability of having found a job does not markedly increase during the eligibility period, but remains positive until day 180 after spell start, and is zero thereafter.

Using the above procedure, we estimate that the YJG implied a reduction in unemployment duration by 1.7 days on average. Calculated this way, the effect appears modest; as discussed in Section V.B, the effects that we find appear comparable to those found in the earlier literature, but there are also examples of previous papers that find substantially larger effects (naturally subject to various caveats regarding the comparability of different studies). 
To get an estimate of the individuals' earnings, we use the average monthly wage among the 24-year-olds who find employment within a year from registration at the PES. As described in Section IV, the wage is measured in the fall each year and is available for all employees in the public sector and for about $50 \%$ of those employed in the private sector. We use wage information from the year after the person registered at the PES, and at that point we have wage data for about $30 \%$ of the 24 -year-olds. The average full-time equivalent wage corresponds to SEK $21,977^{32}$, and on average the individuals worked $84.5 \%$ of full time. Hence, monthly average earnings correspond to SEK 18,571. Earnings for 1.7 additional days of employment then correspond to SEK 1,503 (assuming 21 work days per month). This increase in employment will generate increased tax payments amounting to SEK 607.2 from income as well as payroll taxes. ${ }^{33}$

Reduced income transfers due to increased employment: The reduction in unemployment duration will also lead to a reduction in income transfers. Since the increased flow to employment mainly occurs before program participation, we can use average UI benefits among the 24-year-olds, measured at the beginning of the unemployment spell, as a proxy for daily income transfers. ${ }^{34}$ On average the individuals received daily payments amounting to SEK 151.7. Since income transfers are subject to income taxes (roughly $17 \%$ for this level of income), the 1.7 days of reduction in unemployment duration implies reduced transfers of SEK 214 per person on average.

Program costs: To calculate the costs of YJG, we require an assessment of the costs to the PES of operating the program. For simplicity, we ignore potential effects on the compensation paid to the participants of the program (while still unemployed). Participation in the YJG implies a small reduction in transfers for some UI recipients. However, for those unemployed persons who are not entitled to UI benefits, income transfers may instead increase as all participants are given a small monetary compensation. To assess how individuals' income 
transfers are affected while participating in the program, we would need to know to what extent these types of changes are offset by changes in means-tested social assistance. Since we only have yearly family-based data on social assistance, we are unable to make such assessments.

The statistics department at the PES has helped us to compute total program costs (excluding compensation to participants) for 2009. In total, the cost of operation amounted to SEK 329 million. ${ }^{35}$ We divide this number by the total number of participation weeks for the same year (which we can compute from our administrative data) to get an estimate of the weekly cost per participant. This procedure gives us an estimate of SEK 188.2 per week, and we assume that the cost was the same the year before as well as the year after. On average, 24-year-olds in our sample participated in the YJG for 9.2 weeks. (Note that this is averaged over all 24-year-olds in our sample, i.e. the figure takes into account incomplete program take-up, and is therefore consistent with the way that the benefits of the program are calculated above.) This calculation gives us an average cost per person of SEK 1,731.4.

Although the program costs seem rather modest, this assessment suggests that the gains in terms of quicker transitions to employment were too small for the program to generate a positive impact on the government budget overall. In sum, the gains (SEK 607.2 + SEK 214) only amount to about a half of the program costs (SEK 1,731.4).

On top of the limitations that have already been highlighted above, it is important to emphasize that this cost-benefit calculation corresponds to 24 -year-olds only, although the target group for the YJG is much broader.

\section{Conclusion}

In this paper, we start by pointing out that within a search-theoretic framework where job seekers differ in their underlying job-finding probability, individual responses to activation 
policies are likely to follow a certain type of pattern: Individuals with a high job-finding probability respond already to the threat of activation, whereas individuals with a low jobfinding probability might catch up during the actual activation phase. The former effect points towards a screening role of activation policies, whereas the latter effect would imply that activation truly helps those in need of assistance.

We used a regression discontinuity design to study the existence of this type of response pattern in the context of an activation program targeted at young unemployed individuals (the Youth Job Guarantee program) introduced in Sweden in 2007. The program is a major countrywide activation policy that affects all young unemployed persons below the age of 25 . The data used cover the whole population of job-seekers. The main novelty of the dataset is that it contains very detailed information on individual characteristics, including register data on health and unemployment history. We use this data to predict individual job-finding probabilities (in the absence of activation) and conduct sub-sample analysis using a procedure that avoids the problem of endogenous stratification.

Our results show that there is a statistically significant and robust threat effect associated with the program; program eligibility increases the probability of finding work before the program starts by about $6 \%$. The threat effect indeed follows a pattern consistent with the screening hypothesis: The threat effect appears to be mainly driven by individuals in a relatively good labor market position. On the other hand, we find no statistically significant threat effect among individuals with characteristics that predict poor prospects of finding a job (e.g. low level of education, immigrant background, or poor mental health). We do not find any longer-term effects of the program: less than a year after registration at the employment service, job-finding among ineligible persons seems to have caught up with that of eligible persons. 
Mandatory activation can be seen as a way to reduce the moral hazard related to unemployment insurance, and the analysis in this paper indicates that it may indeed serve this purpose by screening those who are less in need of support away from the pool of transfer recipients. Hence, activation may be a way to preserve efficiency while maintaining high replacement rates for the unemployed. However, this policy conclusion comes with two important caveats. The first is that the size of the impact of the policy is modest, perhaps because the coverage of the actual activation (the take-up) could be higher. Our assessment is also that the gains were too small for the program to generate a positive impact on the government budget. Secondly, and perhaps more importantly, the type of policy conducted in Sweden was clearly not sufficiently supportive for those with challenging labor market prospects. Instead of training geared towards enhancing job-seeking skills, these youngsters are likely to need more thorough support, such as counseling, further education and greater emphasis on improved health. 


\section{References}

Abadie, Alberto, Matthew M. Chingos, and Martin R. West. 2016. "Endogenous Stratification in Randomized Experiments.” NBER Working Paper No. 19742.

Altmann, Steffen, Armin Falk, Simon Jäger, and Florian Zimmermann. 2016. "Learning about Job Search: A Field Experiment with Job Seekers in Germany.” IZA Discussion Paper No. 9040.

Andersen, Torben M., and Michael Svarer. 2014. 'The Role of Workfare in Striking a Balance between Incentives and Insurance in the Labour Market." Economica 81(321): 86116.

Bergemann, Annette, Marco Caliendo, Gerard J. van den Berg, and Klaus F. Zimmermann. 2011. "The Threat Effect of Participation in Active Labor Market Programs on Job Search Behavior of Migrants in Germany." International Journal of Manpower 32(7): 777-795.

Besley, Timothy, and Stephen Coate. 1992. "Workfare versus Welfare: Incentive Arguments for Work Requirements in Poverty-Alleviation Programs.” American Economic Review 82(1): 249-261.

Black, Dan A., Jeffrey A. Smith, Mark C. Berger, and Brett J. Noel. 2003. "Is the Threat of Reemployment Services More Effective than the Services Themselves? Evidence from Random Assignment in the UI System.” American Economic Review 93(4): 1313-1327.

Caliendo, Marco, Steffen Kunn, and Ricarda Schmidl. 2011. "Fighting Youth Unemployment: The Effects of Active Labor Market Policies.” IZA Discussion Paper No. 6222.

Calonico, Sebastian, Matias D. Cattaneo, and Rocio Titunik. 2014. "Robust Nonparametric Confidence Intervals for Regression-Discontinuity Designs.” Econometrica 82(6): 22952326. 
Card, David, Jochen Kluve, and Andrea Weber. 2018. "What Works? A Meta Analysis of Recent Active Labor Market Program Evaluations." Journal of the European Economic Association 16(3): 894-931.

Carling, Kenneth, and Laura Larsson. 2005. "Does Early Intervention Help the Unemployed Youth?" Labour Economics 12(3): 301-319.

Cuff, Katherine. 2000. “Optimality of Workfare with Heterogeneous Preferences." Canadian Journal of Economics 33(1): 149-174.

DellaVigna, Stefano, and M. Daniele Paserman. 2005. "Job Search and Impatience.” Journal of Labor Economics 23(3): 527-588.

Edmark, Karin, Che-Yuan Liang, Eva Mörk, and Håkan Selin. 2012. "Evaluation of the Swedish Earned Income Tax Credit.” IFAU Working Paper No. 2012:1

Forslund Anders, and Oskar Nordström Skans. 2006. ”Swedish Youth Labor Market Policies Revisited." Vierteljahrshefte zur Wirtschaftsforschung, (Quarterly Journal of Economic Research) 75(3): 168-185.

Fredriksson, Peter, and Bertil Holmlund. 2006a. “Optimal Unemployment Insurance Design: Time limits, Monitoring, or Workfare?” International Tax and Public Finance 13: 565585.

2006b. "Improving Incentives in Unemployment Insurance: A review of Recent Research.” Journal of Economic Surveys 20(3): 357-386.

Geerdsen, Lars P. 2006. "Is there a Threat Effect of Labour Market Programs? A Study of ALMP in the Danish UI System.” Economic Journal 116(513): 738-750.

Government Bill (2009/10:1), 2010 års budgetproposition. 
Graversen, Brian Krogh, and Brian Larsen. 2013. ”Is there a Threat Effect of Mandatory Activation Programs for the Long-term Unemployed?" Empirical Economics 44: 10311051.

Hall, Robert E. 2005. "Employment Fluctuations with Equilibrium Wage Stickiness.” American Economic Review 95(1): 50-65.

Hägglund, Pathric. 2011. “Are There Pre-program Effects of Active Placement Efforts? Evidence from a Social Experiment.” Economics Letters 112(1): 91-93.

Hämäläinen, Kari, Ulla Hämäläinen, and Juha Tuomala. 2014. 'The Labour Market Impacts of Youth Guarantee: Lessons for Europe?” VATT Working Papers No. 60.

Imbens, Guido, and Karthik Kalyanaraman. 2012. "Optimal Bandwidth Choice for the Regression Discontinuity Estimator.” Review of Economic Studies 79: 933-959.

Kluve, Jochen, Susana Puerto, David Robalino, Jose M. Romero, Jose M. Rother, Jonathan Stöterau, Felix Weidenkaff, and Marc Witte. 2019. "Do Youth Employment Programs Improve Labor Market Outcomes? A Quantitative Review.” World Development 114 (February): 237-253.

Kreiner, Claus Thustrup, and Torben Tranaes. 2005. “Optimal Workfare with Voluntary and Involuntary Unemployment.” Scandinavian Journal of Economics 107(3): 459-474.

Lee, David S., and Thomas Lemieux. 2010. "Regression Discontinuity Designs in Economics.” Journal of Economic Literature 48(2): 281-355.

Maibom, Jonas, Michael Rosholm, and Michael Svarer. 2014. "Can Active Labour Market Policies Combat Youth Unemployment?” IZA Discussion Paper No. 7912. 2017. "Experimental Evidence on the Effects of Early Meetings and Activation." Scandinavian Journal of Economics, 119(3): 541-570. 
Martinsson, Sara, and Kristina Sibbmark. 2010. "Vad gör de i jobbgarantin för ungdomar?" IFAU Report No. 2010:22.

McCrary, Justin. 2008. "Manipulation of the Running Variable in the Regression Discontinuity Design: A Density Test.” Journal of Econometrics 142(2): 698-714.

Nekoei, Arash, and Andrea Weber. 2017. "Does Extending Unemployment Benefits Improve Job Quality?” American Economic Review 107(2): 527-61.

Pirttilä, Jukka, and Håkan Selin. 2011. ’Skattepolitik och sysselsättning. Hur väl klarar sig det svenska systemet?” In Välfärdsstaten i arbete - omfördelning och inkomsttrygghet med incitament till arbete, SOU 2011:2.

Rosholm, Michael, and Michael Svarer. 2008. "The Threat Effect of Active Labour Market Programs." Scandinavian Journal of Economics 110(2): 385-401.

Tuomala, Juha. 2011. "The Threat Effect of Mandatory Programs in Finland.” LABOUR 25(4): 508-527.

Van den Berg, Gerard, and Johan Vikström. 2014. ”Monitoring Job Offers Decisions, Punishments, Exit to Work, and Job Quality.” Scandinavian Journal of Economics 116(2): 284-334. 


\section{Figures for the main text}

\begin{tabular}{|c|c|c|}
$\begin{array}{c}\text { Open unemployment } \\
\text { and registration at } \\
\text { the PES } \\
\text { (3 months) }\end{array}$ & $\rightarrow$ & $\begin{array}{c}\text { The Youth Job Guarantee }: \\
\text { - In-depth assessment and counseling } \\
\text { - Job-seeking activities with coaching } \\
\text { (at least 3 months, normally) }\end{array}$
\end{tabular}$\rightarrow \begin{gathered}\text { The Youth Job Guarantee: } \\
\text { - Work experience or training } \\
\text { - Job-seeking activities at least 4h/week } \\
\text { (12 months, max 15 months in total) }\end{gathered}$

Figure 1: The Youth Job Guarantee Program 


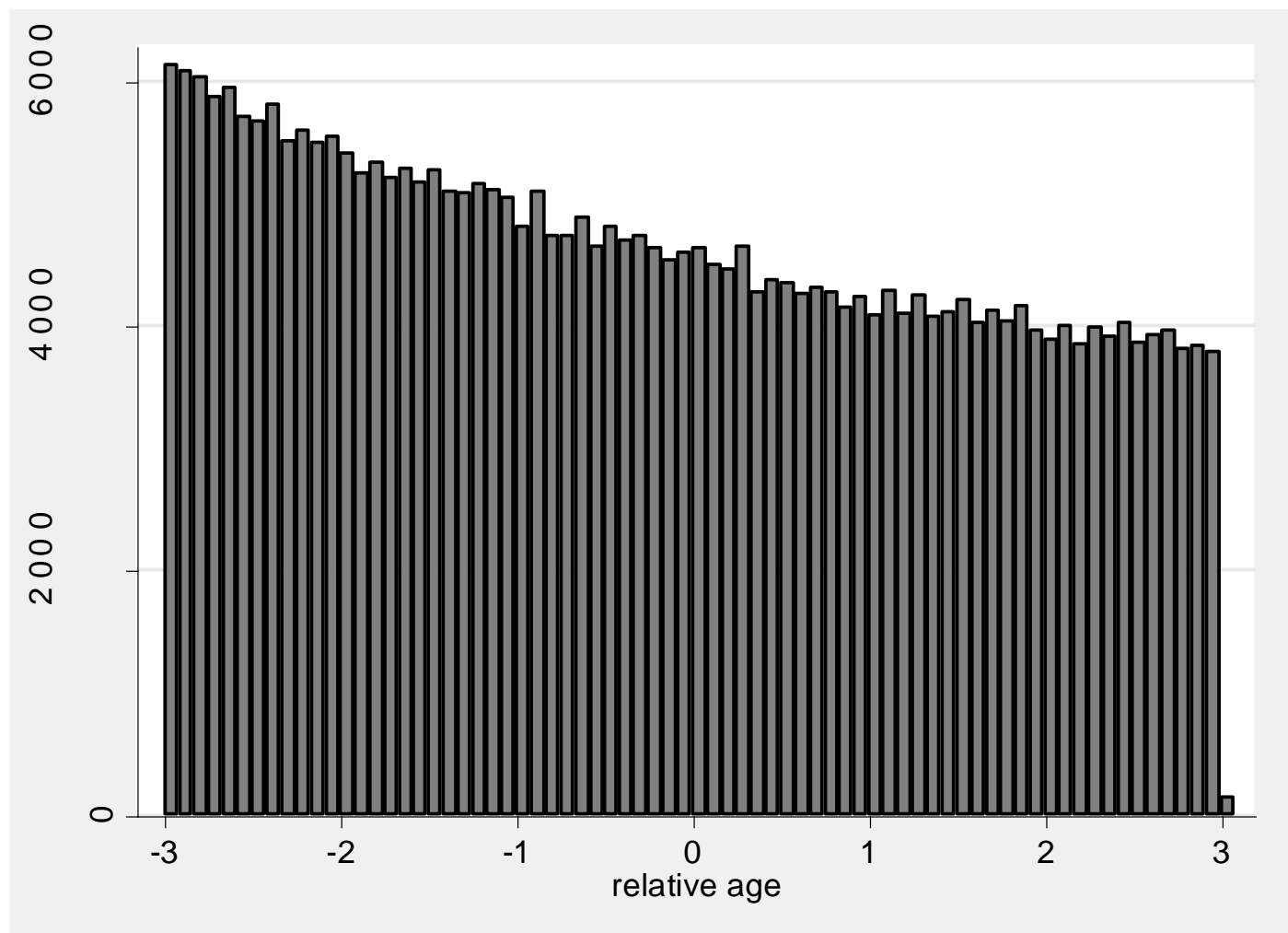

Figure 2: Number of individuals entering unemployment, by age at day 90 of the unemployment spell

Note: Age in years relative to the cut-off age of 25 on the $\mathrm{x}$-axis. 


\section{Kaplan-Meier survival estimates}

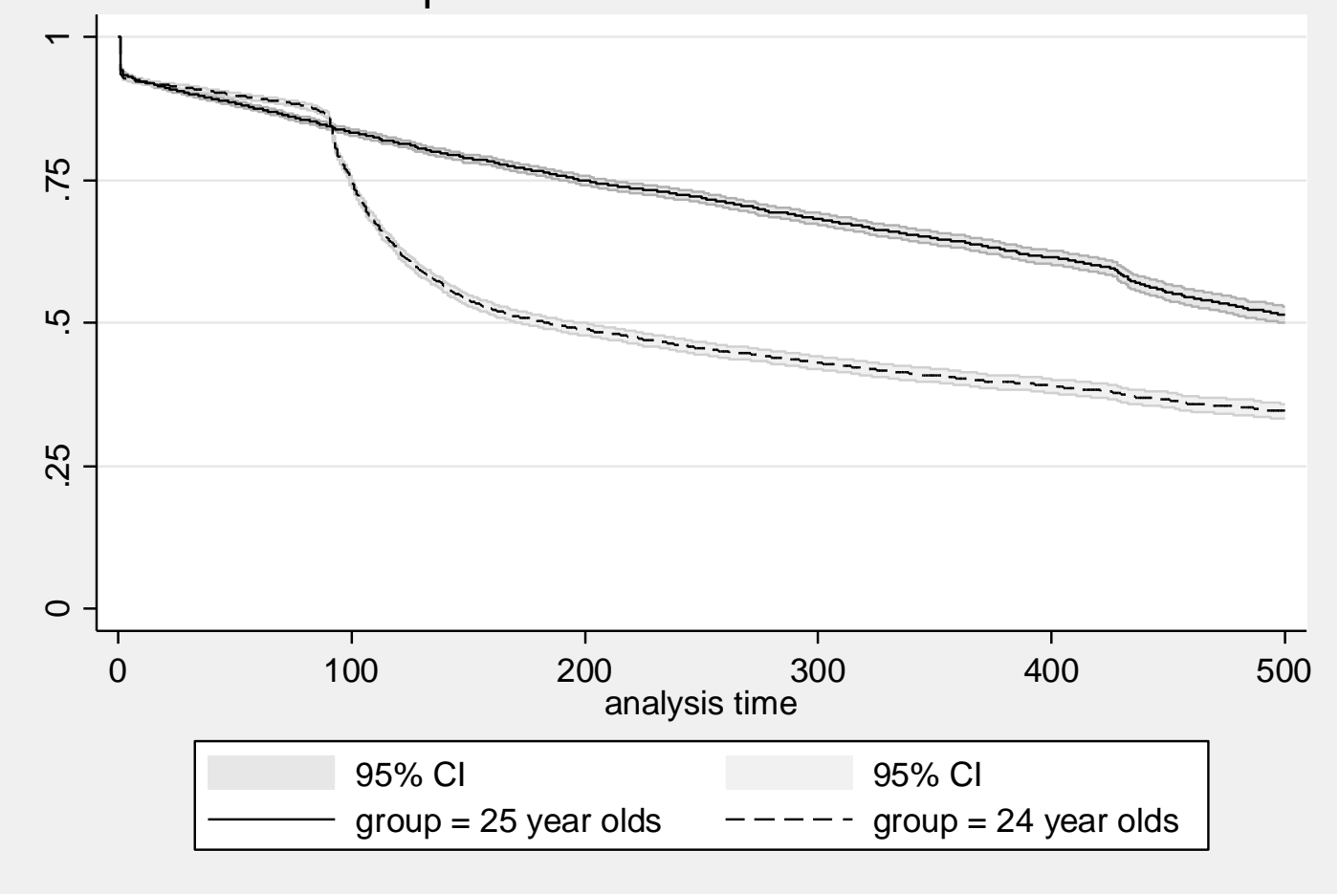

Figure 3: Kaplan-Meier survival estimates for duration until program start for 24- and 25year-olds in 2008 - 2010.

Note: The figure shows the probability of remaining in open unemployment relative to starting any labor market program at different points of time during the unemployment spell. The individuals are divided into groups based on their age 90 days after entering unemployment. The sample is limited to 24 - and 25 -year-olds born in the same calendar year. 

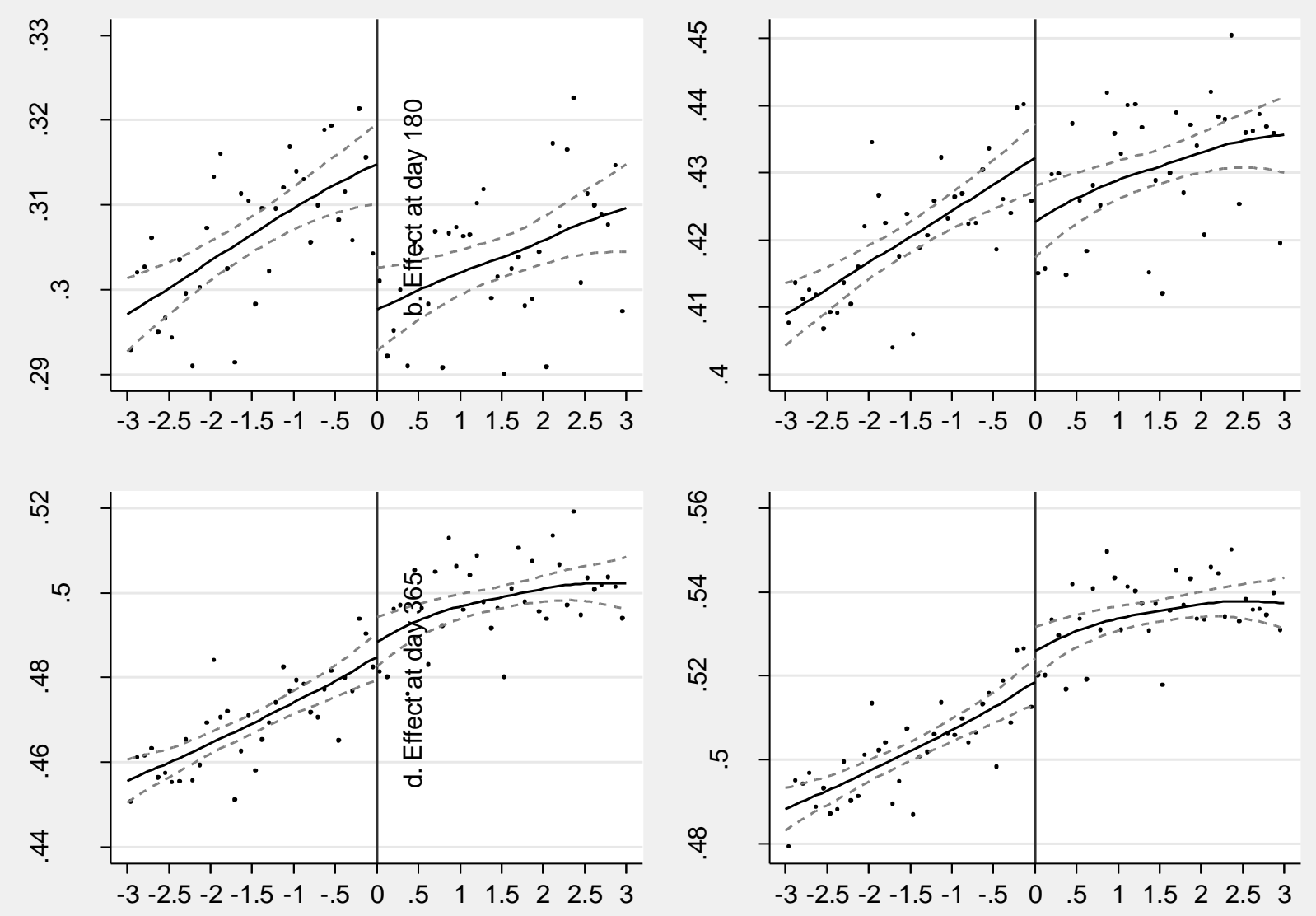

Figure 4: Effects of program eligibility on the probability of finding employment

Note: Age in years relative to the cut-off age of 25 on the $\mathrm{x}$-axes and indicators for becoming employed during the first 90, 180, 270 and 365 days of unemployment on the y-axes. Age refers to the individual's age 90 days after entering unemployment. 


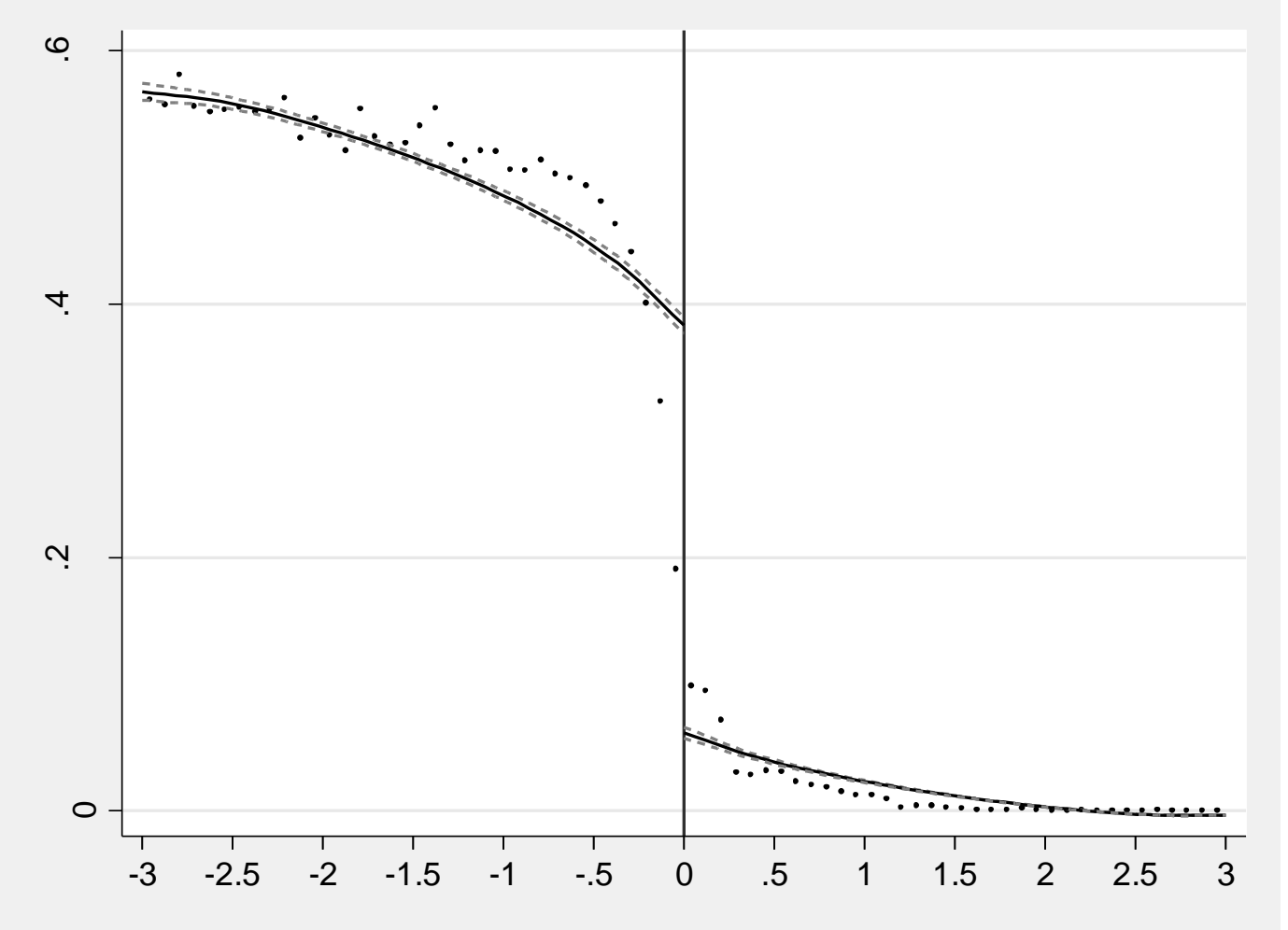

\section{Figure 5: Youth Job Guarantee take-up}

Note: Age in years relative to the cut-off age of 25 on the $\mathrm{x}$-axis and an indicator for participating in the program on the y-axis. Age refers to the individual's age 90 days after entering unemployment. The figure is drawn only for individuals whose spell lasted over 90 days. 

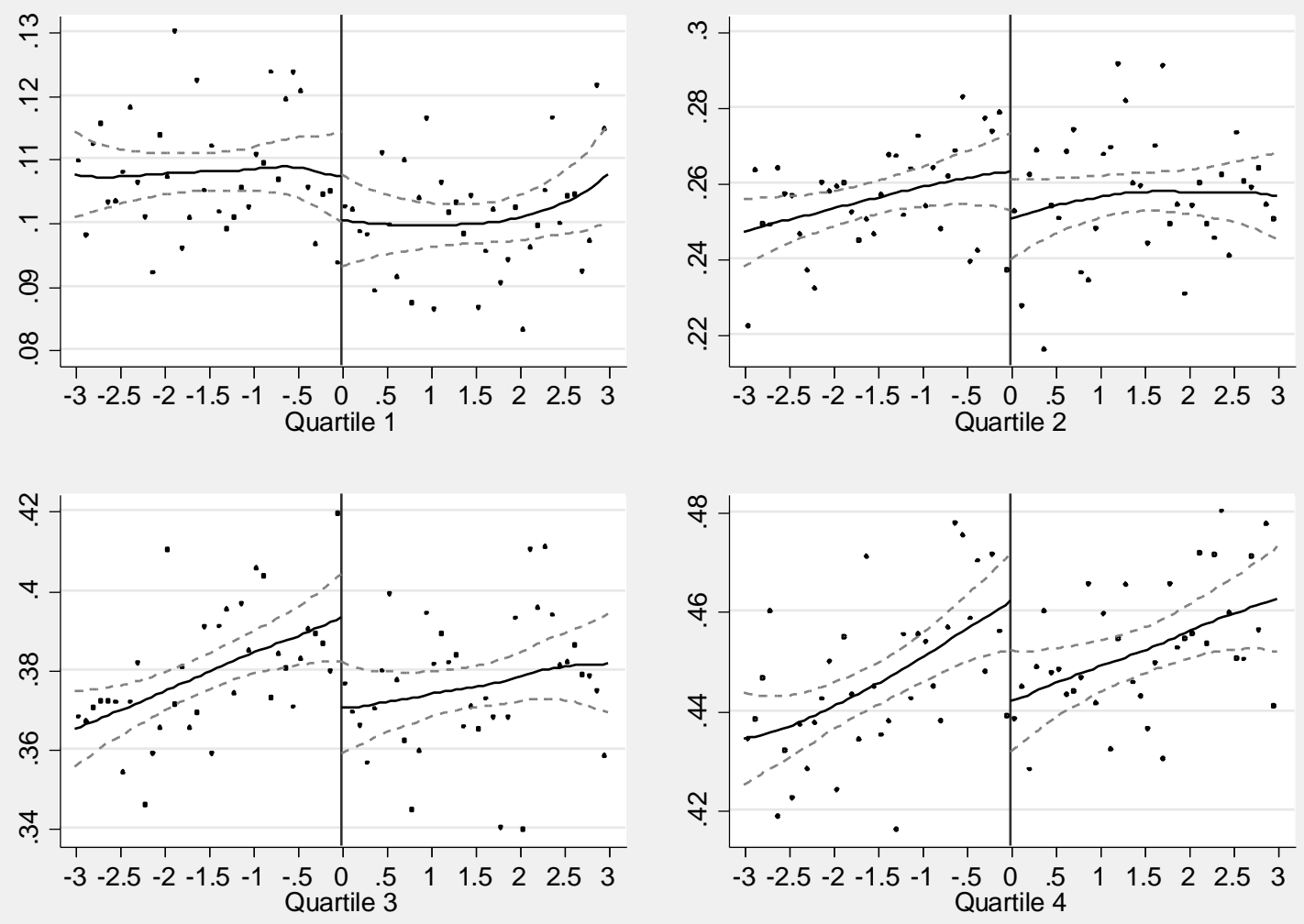

Figure 6: Effects of program eligibility on the probability of becoming employed by day 90, by quartiles

Note: Age in years relative to the cut-off age of 25 on the x-axes and indicators for becoming employed during the first 90 days of unemployment on the y-axes. Age refers to the individual's age 90 days after entering unemployment. 

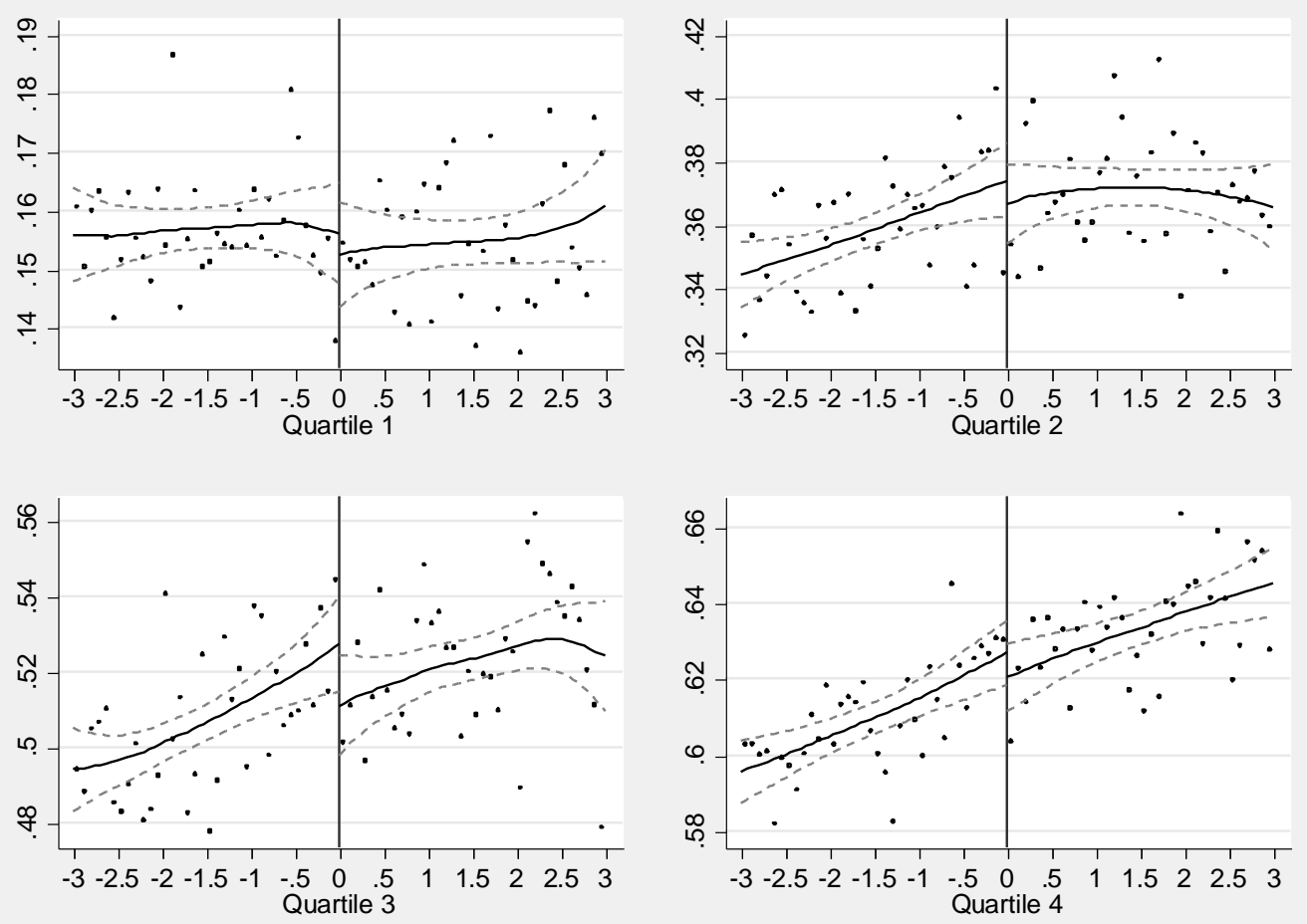

Figure 7: Effects of program eligibility on the probability of becoming employed by day 180, by quartiles

Note: Age in years relative to the cut-off age of 25 on the x-axes and indicators for becoming employed during the first 180 days of unemployment on the y-axes. Age refers to the individual's age 90 days after entering unemployment. 

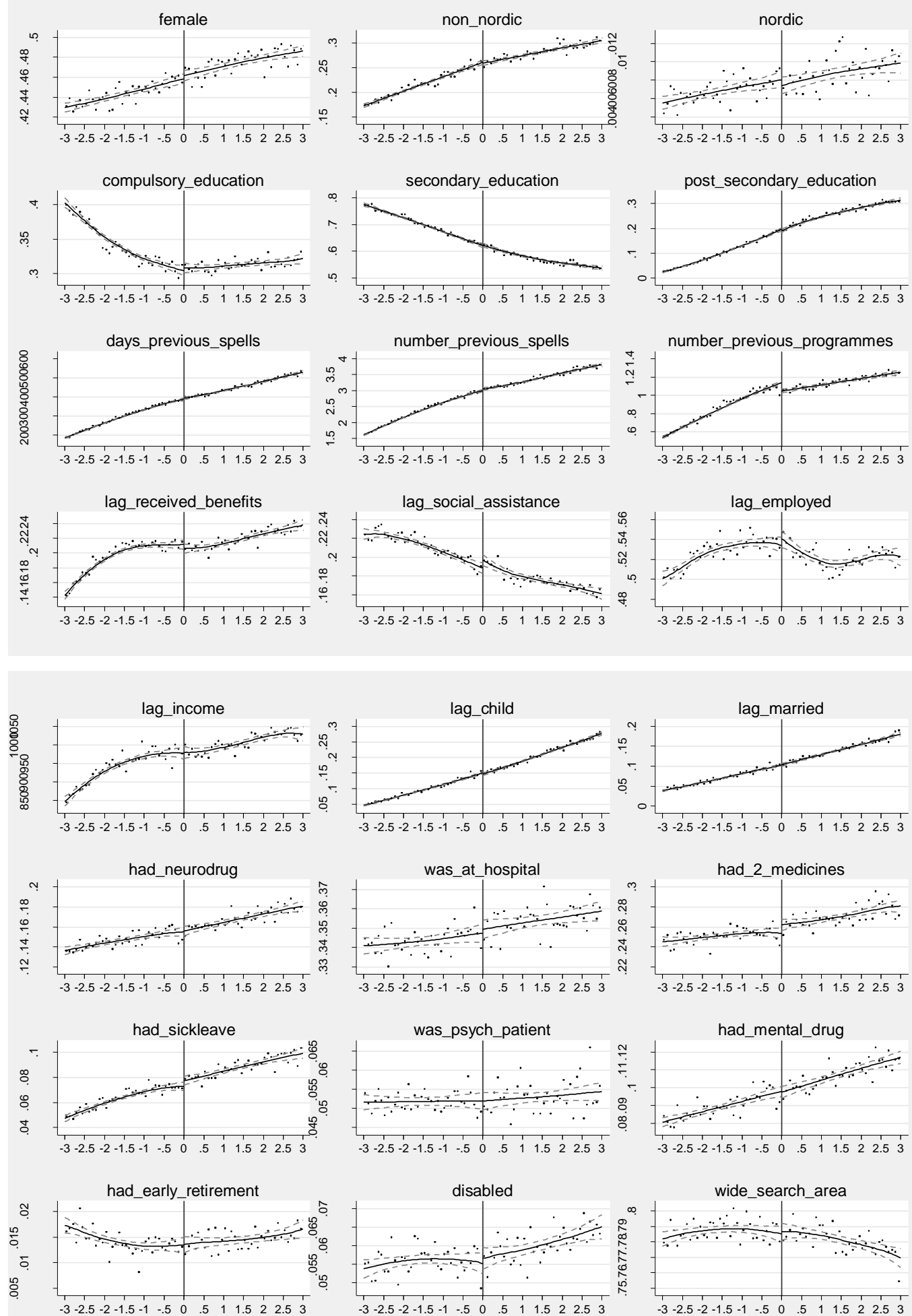

Figure 8: Balance of background variables.

Note: Age in years relative to the cut-off age of 25 on the x-axes. Age refers to the individual's age 90 days after entering unemployment. Education level and presence of children are measured in 2007, all other lagged variables as well as the sickness variables are measured the year prior to the start of the unemployment spell. The remaining variables are measured upon registration at the PES, i.e. at the start of the spell. "Nordic" means born in another Nordic country (not Sweden). "Non-Nordic" means born outside the Nordic countries. "Wide search area" means that the person is interested in jobs within a wider geographical area. Full variable names are given in Tables 1 and 2. 


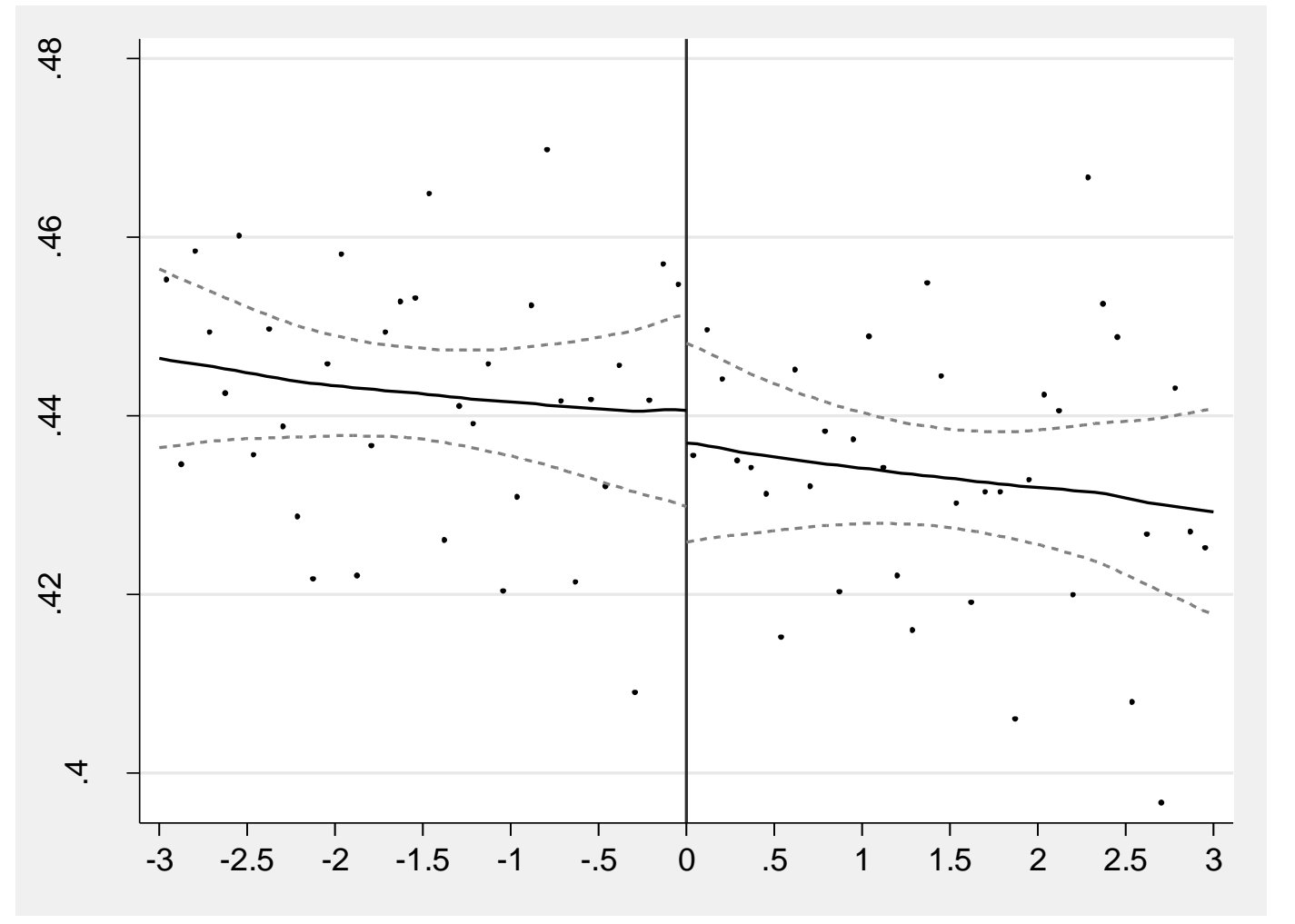

Figure 9: Placebo test: Threat effect in 2007

Note: Age in years relative to the cut-off age of 25 on the $\mathrm{x}$-axis and an indicator for becoming employed during the first 90 days of unemployment on the y-axis. Age refers to the individual's age 90 days after entering unemployment. 


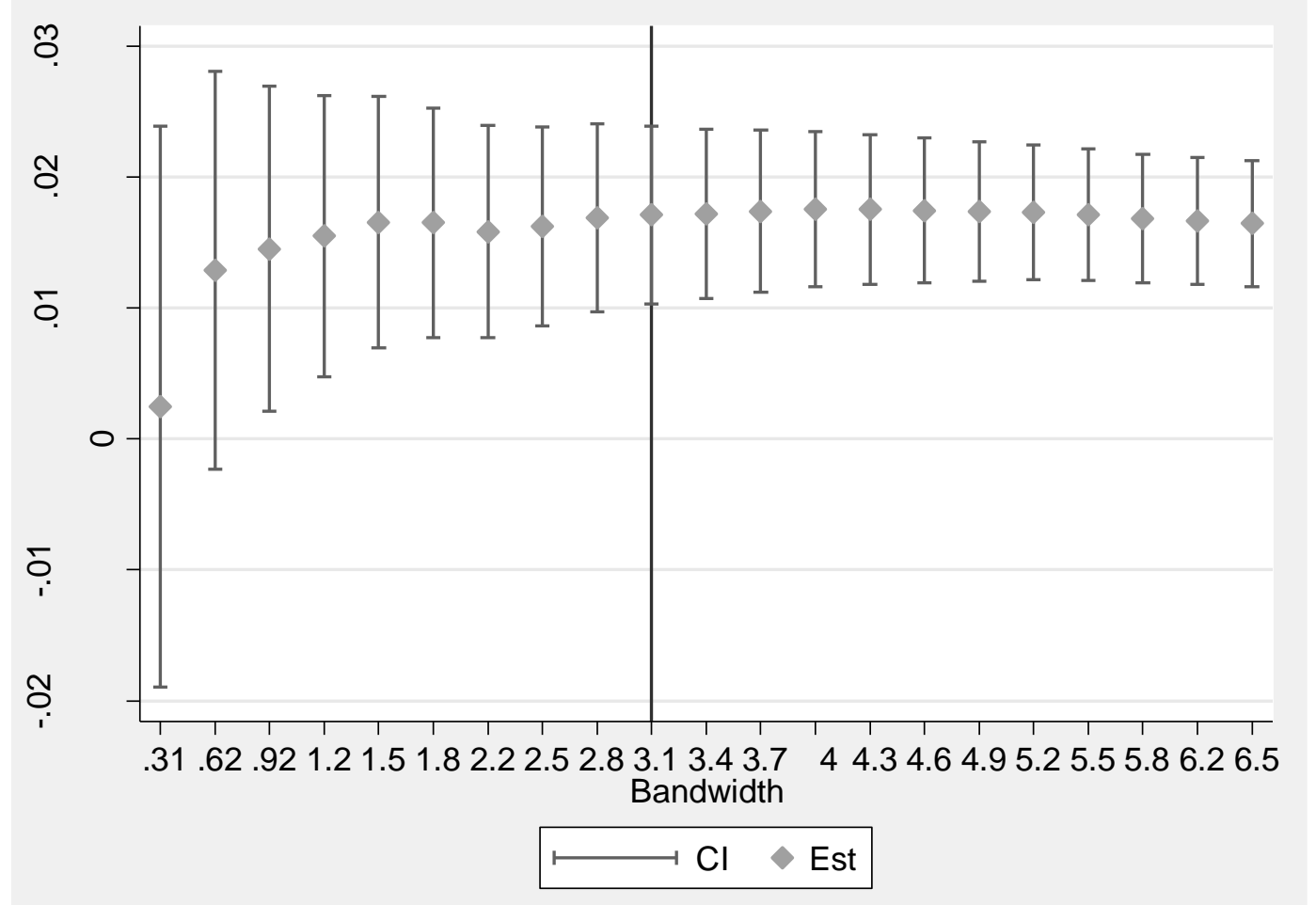

Figure 10: The RD estimate of the threat effect as a function of bandwidth Note: The vertical line marks the Imbens-Kalyanaraman optimal bandwidth. 


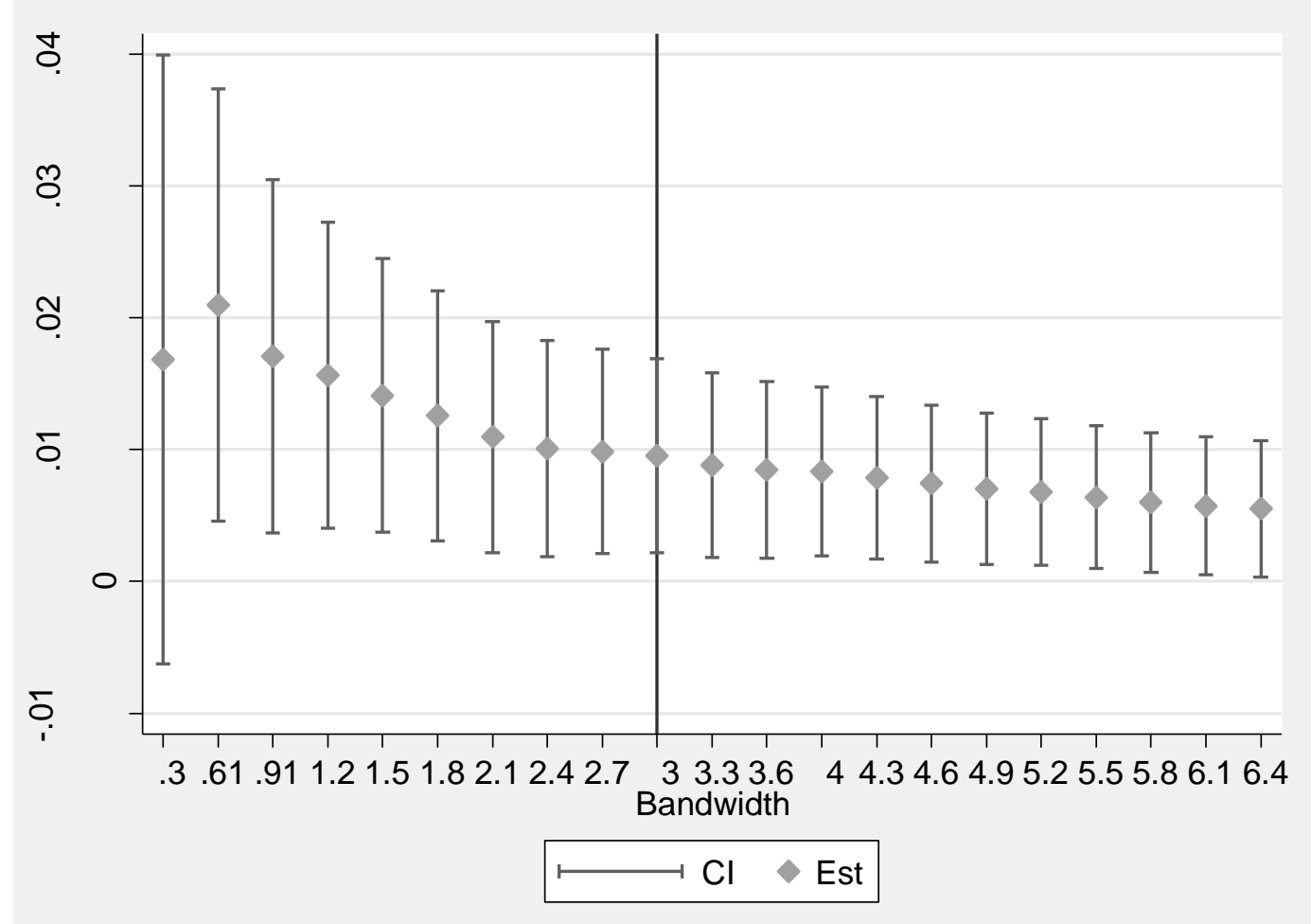

Figure 11: The RD estimate of the effect on day 1-180 as a function of bandwidth Note: The vertical line marks the Imbens-Kalyanaraman optimal bandwidth. 


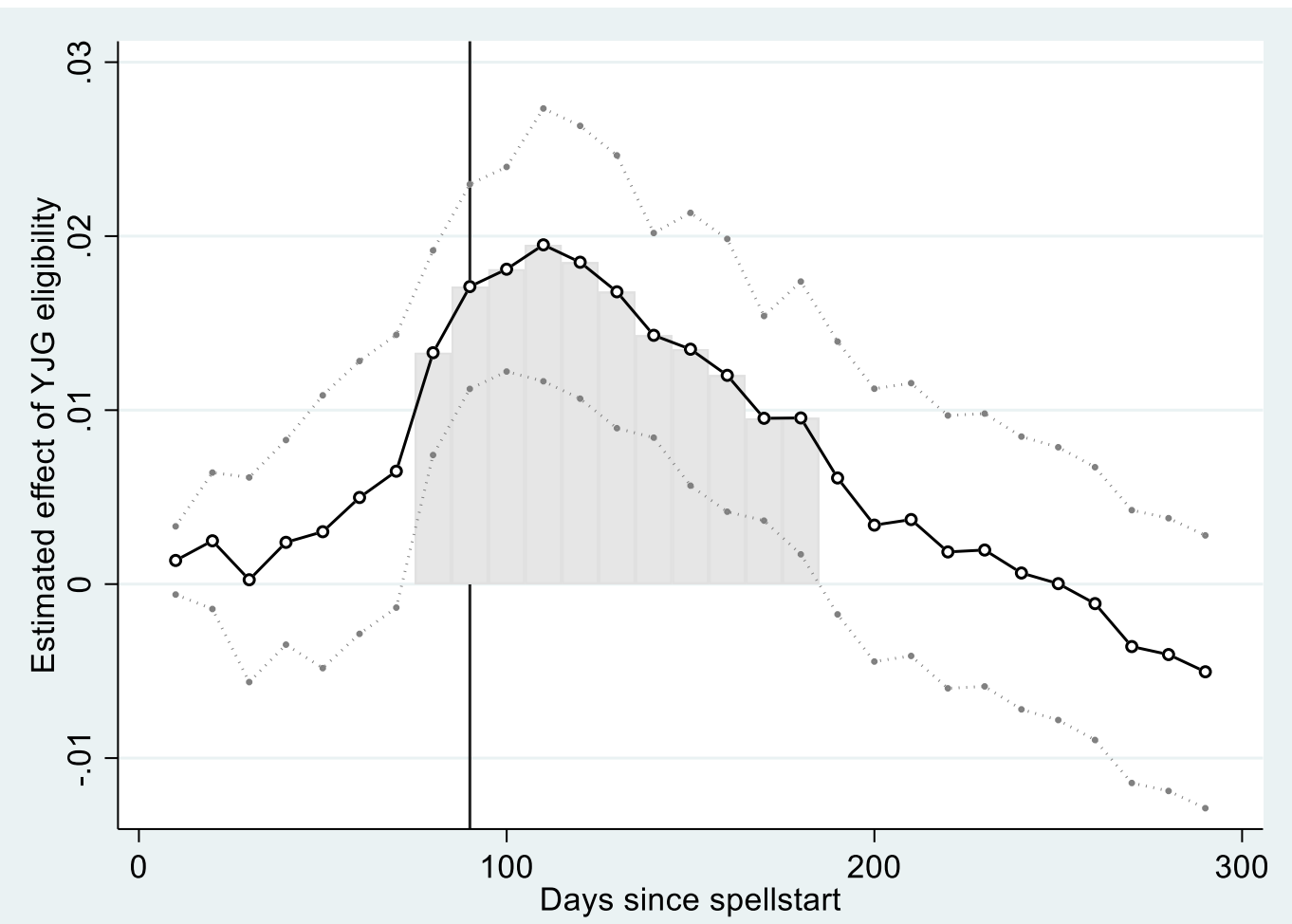

Figure 12. Calculating the effect of YJG on the average duration of unemployment. Note: The figure shows the estimated effect of YJG eligibility on the likelihood of having found a job at each point in time since the start of the unemployment spell. The area below the line gives an estimate of the effect of the YJG on the average duration of unemployment. This is approximated by the area shown by the grey bars.

The vertical line marks the time when program eligibility starts (day 90 of the unemployment spell). 


\section{Tables for the main text}

Table 1

Descriptive statistics for our sample

\begin{tabular}{|c|c|c|c|c|c|c|c|c|c|c|c|c|}
\hline & \multicolumn{3}{|c|}{ All } & \multicolumn{3}{|c|}{ All in the YJG program } & \multicolumn{3}{|c|}{ 24-year-olds } & \multicolumn{3}{|c|}{ 25-year-olds } \\
\hline & $\begin{array}{c}\text { Observa- } \\
\text { tions }\end{array}$ & Mean & $\begin{array}{l}\text { Standard } \\
\text { deviation }\end{array}$ & $\begin{array}{c}\text { Observa- } \\
\text { tions }\end{array}$ & Mean & $\begin{array}{r}\text { Standard } \\
\text { deviation }\end{array}$ & $\begin{array}{c}\text { Observa- } \\
\text { tions }\end{array}$ & Mean & $\begin{array}{r}\text { Standard } \\
\text { deviation } \\
\end{array}$ & $\begin{array}{c}\text { Observa- } \\
\text { tions }\end{array}$ & Mean & $\begin{array}{r}\text { Standard } \\
\text { deviation }\end{array}$ \\
\hline $\begin{array}{l}\text { Number of days in previous } \\
\text { unemployment spells }\end{array}$ & 702,087 & 288.8 & 410.4 & 149,167 & 202.0 & 267.9 & 57,076 & 363.0 & 369.4 & 52,439 & 410.6 & 422.1 \\
\hline Number of previous spells & 702,087 & 2.232 & 2.618 & 149,167 & 1.520 & 1.700 & 57,076 & 2.825 & 2.390 & 52,439 & 3.143 & 2.708 \\
\hline Number of previous programs & 702,087 & 0.769 & 1.680 & 149,167 & 1.116 & 1.611 & 57,076 & 1.047 & 1.799 & 52,439 & 1.076 & 1.910 \\
\hline Age at spell start+90 days & 702,087 & 23.77 & 3.185 & 149,167 & 21.67 & 1.627 & 57,076 & 24.49 & 0.289 & 52,439 & 25.49 & 0.289 \\
\hline Country of birth, Non-Nordic & 702,087 & 0.208 & 0.406 & 149,167 & 0.137 & 0.344 & 57,076 & 0.247 & 0.431 & 52,439 & 0.266 & 0.442 \\
\hline Male & 702,087 & 0.550 & 0.498 & 149,167 & 0.598 & 0.490 & 57,076 & 0.546 & 0.498 & 52,439 & 0.534 & 0.499 \\
\hline Unemployment benefits, 2007 & 670,518 & 0.141 & 0.348 & 146,738 & 0.0925 & 0.290 & 53,718 & 0.235 & 0.424 & 49,006 & 0.232 & 0.422 \\
\hline Married, 2007 & 670,518 & 0.0709 & 0.257 & 146,738 & 0.0220 & 0.147 & 53,718 & 0.0779 & 0.268 & 49,006 & 0.101 & 0.302 \\
\hline Social assistance, 2007 & 670,518 & 0.177 & 0.382 & 146,738 & 0.160 & 0.367 & 53,718 & 0.208 & 0.406 & 49,006 & 0.199 & 0.399 \\
\hline Employed, Nov. 2007 & 670,518 & 0.450 & 0.498 & 146,738 & 0.350 & 0.477 & 53,718 & 0.580 & 0.494 & 49,006 & 0.580 & 0.494 \\
\hline Income from work (SEK 100), 2007 & 670,518 & 718.1 & 887.4 & 146,738 & 508.4 & 732.5 & 53,718 & 983.9 & 955.5 & 49,006 & 1,010 & 990.1 \\
\hline Children, 2007 & 702,087 & 0.122 & 0.328 & 149,167 & 0.0415 & 0.199 & 57,076 & 0.131 & 0.337 & 52,439 & 0.166 & 0.372 \\
\hline Compulsory education & 649,897 & 0.484 & 0.500 & 143,173 & 0.609 & 0.488 & 52,294 & 0.313 & 0.464 & 47,721 & 0.308 & 0.462 \\
\hline Upper secondary education ( 3 years) & 649,897 & 0.389 & 0.488 & 143,173 & 0.362 & 0.481 & 52,294 & 0.526 & 0.499 & 47,721 & 0.470 & 0.499 \\
\hline Post-secondary education & 649,897 & 0.127 & 0.333 & 143,173 & 0.0287 & 0.167 & 52,294 & 0.161 & 0.368 & 47,721 & 0.222 & 0.416 \\
\hline
\end{tabular}


Table 2

Some health indicators, previous year

\begin{tabular}{|c|c|c|c|c|c|c|c|c|}
\hline & \multicolumn{2}{|c|}{$\begin{array}{l}\text { Other 24- and 25- } \\
\text { year-olds } \\
\text { (not unemployed) }\end{array}$} & \multicolumn{2}{|c|}{$\begin{array}{l}\text { All in the YJG } \\
\text { program }\end{array}$} & \multicolumn{2}{|c|}{$\begin{array}{l}\text { 24-year-olds } \\
\text { (in our sample) }\end{array}$} & \multicolumn{2}{|c|}{$\begin{array}{l}25 \text {-year-olds } \\
\text { (in our sample) }\end{array}$} \\
\hline & Mean & $\begin{array}{l}\text { Standard } \\
\text { deviation }\end{array}$ & Mean & $\begin{array}{l}\text { Standard } \\
\text { deviation }\end{array}$ & Mean & $\begin{array}{l}\text { Standard } \\
\text { deviation }\end{array}$ & Mean & $\begin{array}{l}\text { Standard } \\
\text { deviation }\end{array}$ \\
\hline \multirow{2}{*}{$\begin{array}{l}\text { Number of prescriptions } \\
\text { Had drug for neurological } \\
\text { condition }\end{array}$} & 1.771 & 2.920 & 1.679 & 2.580 & 1.867 & 2.960 & 1.924 & 3.036 \\
\hline & 0.117 & 0.322 & 0.115 & 0.319 & 0.154 & 0.361 & 0.160 & 0.367 \\
\hline \multirow{2}{*}{$\begin{array}{l}\text { Had drug for mental illness }{ }^{\mathrm{a}} \\
\text { Received sickness benefits }\end{array}$} & 0.0683 & 0.252 & 0.0645 & 0.246 & 0.0959 & 0.294 & 0.100 & 0.300 \\
\hline & 0.0528 & 0.224 & 0.0340 & 0.181 & 0.0714 & 0.258 & 0.0806 & 0.272 \\
\hline Received disability pension & 0.0196 & 0.138 & 0.00971 & 0.0981 & 0.0136 & 0.116 & 0.0139 & 0.117 \\
\hline Was treated at a hospital ${ }^{\mathrm{b}}$ & 0.298 & 0.458 & 0.317 & 0.465 & 0.347 & 0.476 & 0.351 & 0.477 \\
\hline Was a psychiatric patient ${ }^{\mathrm{b}}$ & 0.0317 & 0.175 & 0.0385 & 0.192 & 0.0521 & 0.222 & 0.0528 & 0.224 \\
\hline Number of observations & 301,134 & & 149,167 & & 57,076 & & 52,439 & \\
\hline
\end{tabular}

Note: a. Drugs for mental illness is a subset of neurological drugs. b. Includes both inpatient and outpatient care. 
Table 3

Estimated effects of being eligible for the Youth Job Guarantee Program (full sample)

\begin{tabular}{lllll}
\hline & $\begin{array}{l}(1) \\
\text { Threat effect }\end{array}$ & $\begin{array}{l}(2) \\
\text { Effect within } \\
\text { 180 days }\end{array}$ & $\begin{array}{l}(3) \\
\text { Effect within } \\
270 \text { days }\end{array}$ & $\begin{array}{l}\text { Effect within } \\
365 \text { days }\end{array}$ \\
\hline $\begin{array}{l}\text { Effect of program } \\
\text { eligibility }\end{array}$ & $\begin{array}{l}0.0171^{* * *} \\
(0.003)\end{array}$ & $\begin{array}{l}0.0096^{* *} \\
(0.004)\end{array}$ & $\begin{array}{l}-0.0040 \\
(0.004)\end{array}$ & $\begin{array}{l}-0.0073^{*} \\
(0.004)\end{array}$ \\
$\begin{array}{l}\text { Observations within } \\
\text { bandwidth }\end{array}$ & 347,032 & 342,191 & 287,712 & 291,949 \\
$\begin{array}{l}\text { Bandwidth } \\
\begin{array}{l}\text { Mean of outcome } \\
\text { among 25-year-olds }\end{array}\end{array}$ & 3.078 & 3.039 & 2.579 & 2.614 \\
\hline
\end{tabular}

Notes: Estimates from local linear regressions using a triangle kernel and optimal bandwidth as defined by Imbens-

Kalyanaraman. Standard errors in parentheses. $* / * * / * * *$ denotes significance at the 10/5/1 percent level. 
Table 4

Relationship between background characteristics and the probability of finding employment within 365 days

\begin{tabular}{|c|c|}
\hline & Year 2007 \\
\hline \multirow{2}{*}{ Age at spell start } & $-0.0130 * *$ \\
\hline & $(0.00610)$ \\
\hline \multirow{2}{*}{ Age at spell start, squared } & $0.000306^{* *}$ \\
\hline & $(0.000123)$ \\
\hline \multirow{2}{*}{ Female } & -0.00201 \\
\hline & $(0.00217)$ \\
\hline \multirow{2}{*}{ Only compulsory education } & $-0.148 * * *$ \\
\hline & $(0.00291)$ \\
\hline \multirow{2}{*}{ Post-secondary education } & $0.0460^{* * *}$ \\
\hline & $(0.00345)$ \\
\hline \multirow{2}{*}{ Missing information on education } & $-0.249 * * *$ \\
\hline & $(0.0816)$ \\
\hline \multirow{2}{*}{ Country of birth, Nordic (but not Sweden) } & 0.00176 \\
\hline & $(0.0116)$ \\
\hline \multirow{2}{*}{ Country of birth, Non-Nordic } & $-0.122 * * *$ \\
\hline & $(0.00302)$ \\
\hline \multirow[t]{2}{*}{ Registered disability } & $-0.198 * * *$ \\
\hline & $(0.00520)$ \\
\hline \multirow[t]{2}{*}{ Geographically wide search area } & $0.0472 * * *$ \\
\hline & $(0.00229)$ \\
\hline \multirow[t]{2}{*}{ Has a child } & $-0.0830 * * *$ \\
\hline & $(0.00311)$ \\
\hline \multirow[t]{2}{*}{ Received unemployment benefits } & $0.0476^{* * *}$ \\
\hline & (0.00308) \\
\hline \multirow{2}{*}{ Was married } & 0.00354 \\
\hline & $(0.00484)$ \\
\hline \multirow[t]{2}{*}{ Received social assistance } & $-0.0811 * * *$ \\
\hline & $(0.00345)$ \\
\hline \multirow[t]{2}{*}{ Was employed in Nov. 2006} & $0.0399 * * *$ \\
\hline & $(0.00457)$ \\
\hline \multirow[t]{2}{*}{ Had neuro drug } & $-0.0516 * * *$ \\
\hline & $(0.00398)$ \\
\hline \multirow[t]{2}{*}{ Had been to hospital } & $-0.00514 *$ \\
\hline & $(0.00282)$ \\
\hline \multirow[t]{2}{*}{ Had more than 2 medicines } & $0.0245 * * *$ \\
\hline & $(0.00301)$ \\
\hline \multirow[t]{2}{*}{ Had been on sick leave } & $-0.0138 * * *$ \\
\hline & $(0.00507)$ \\
\hline \multirow[t]{2}{*}{ Had been a psychiatric patient } & $-0.0541 * * *$ \\
\hline & $(0.00676)$ \\
\hline \multirow[t]{2}{*}{ Had drug for mental illness } & $-0.0190 * * *$ \\
\hline & $(0.00599)$ \\
\hline \multirow[t]{2}{*}{ Received disability pension } & $-0.160 * * *$ \\
\hline & $(0.00938)$ \\
\hline Observations & 196,371 \\
\hline R-squared & 0.158 \\
\hline
\end{tabular}

Notes: OLS estimates. Heteroscedasticity-robust standard errors in parentheses. $* / * * / * * *$ denotes significance at the 10/5/1 percent level. Other variables include splines for lagged income, number. of days in previous unemployment 
spells, number of previous unemployment spells, number of previous ALMPs as well as dummy variables for county and month of spell start. The background variables are measured in 2006 or at the start of the unemployment spell, except for has child, which is measured in 2007. 
Table 5

Effects of being eligible for the YJG program, by quartiles of predicted employment probabilities

\begin{tabular}{|c|c|c|c|c|}
\hline & $\begin{array}{l}\text { (1) } \\
\text { Quartile 1 }\end{array}$ & $\begin{array}{l}\text { (2) } \\
\text { Quartile 2 }\end{array}$ & $\begin{array}{l}\text { (3) } \\
\text { Quartile } 3 \\
\end{array}$ & $\begin{array}{l}(4) \\
\text { Quartile } 4\end{array}$ \\
\hline A. Threat effect & $\begin{array}{l}0.00689 \\
(0.005)\end{array}$ & $\begin{array}{l}0.0126^{*} \\
(0.007)\end{array}$ & $\begin{array}{l}0.0227 * * * \\
(0.008)\end{array}$ & $\begin{array}{l}0.0201 \text { *** } \\
(0.007)\end{array}$ \\
\hline $\begin{array}{l}\text { Observations within bandwidth } \\
\text { Bandwidth } \\
\text { Mean of outcome among } 25 \text {-year-olds }\end{array}$ & $\begin{array}{l}65,643 \\
2.387 \\
0.100\end{array}$ & $\begin{array}{l}66,315 \\
2.828 \\
0.250\end{array}$ & $\begin{array}{l}70,804 \\
2.618 \\
0.371\end{array}$ & $\begin{array}{l}92,840 \\
2.774 \\
0.446\end{array}$ \\
\hline B. Effect within 180 days & $\begin{array}{l}0.00365 \\
(0.006)\end{array}$ & $\begin{array}{l}0.00745 \\
(0.009)\end{array}$ & $\begin{array}{l}0.0165^{*} \\
(0.009)\end{array}$ & $\begin{array}{l}0.00453 \\
(0.006)\end{array}$ \\
\hline $\begin{array}{l}\text { Observations within bandwidth } \\
\text { Bandwidth } \\
\text { Mean of outcome among } 25 \text {-year-olds }\end{array}$ & $\begin{array}{l}62,408 \\
2.273 \\
0.154\end{array}$ & $\begin{array}{l}59,125 \\
2.544 \\
0.367\end{array}$ & $\begin{array}{l}55,667 \\
2.079 \\
0.517\end{array}$ & $\begin{array}{l}141,889 \\
4.206 \\
0.626\end{array}$ \\
\hline
\end{tabular}

Notes: Estimates from local linear regressions using a triangle kernel and optimal bandwidth as defined by Imbens-

Kalyanaraman. Standard errors in parentheses. $* / * * * * * *$ denotes significance at the 10/5/1 percent level. 
Table 6

Robustness to adding covariates (full sample)

\begin{tabular}{lll}
\hline & $\begin{array}{l}\text { Threat effect, } \\
\text { with covariates }\end{array}$ & $\begin{array}{l}\text { Days 1-180, } \\
\text { with covariates }\end{array}$ \\
\hline Effect of program eligibility & $\begin{array}{l}0.0186^{* * *} \\
(0.0032)\end{array}$ & $\begin{array}{l}0.011^{* *} \\
(0.0034)\end{array}$ \\
$\begin{array}{ll}\text { Observations } \\
\text { Bandwidth }\end{array}$ & 347,032 & 342,191 \\
Mean of outcome among 25-year-olds & 0.3078 & 3.039 \\
\hline
\end{tabular}

Notes: Estimates from local linear regressions using a triangle kernel and optimal bandwidth as defined by Imbens-

Kalyanaraman. Standard errors in parentheses. */**/*** denotes significance at the 10/5/1 percent level. 
Table 7

Placebo tests, comparing other age groups

\begin{tabular}{lllll}
\hline & $\begin{array}{l}(1) \\
\text { Effect within } \\
90 \text { days }\end{array}$ & $\begin{array}{l}(2) \\
\text { Effect within } \\
180 \text { days }\end{array}$ & $\begin{array}{l}(3) \\
\text { Effect within } \\
\text { 270 days }\end{array}$ & $\begin{array}{l}\text { (4) } \\
\text { Effect within } \\
\text { 365 days }\end{array}$ \\
\hline & & & & \\
A. 23- vs. 24-year-olds & -0.00397 & -0.000329 & 0.00167 & 0.00282 \\
& $(0.004)$ & $(0.004)$ & $(0.004)$ & $(0.005)$ \\
& & & & \\
Observations & 242,864 & 458,575 & 308,564 & 236,797 \\
Bandwidth & 2.015 & 3.575 & 2.522 & 1.964 \\
Mean of outcome among 24-year-olds & 0.312 & 0.428 & 0.479 & 0.512 \\
\hline & & & & \\
B. 25- vs. 26-year-olds & -0.00329 & -0.000250 & 0.00801 & $0.00784^{*}$ \\
& $(0.004)$ & $(0.004)$ & $(0.005)$ & $(0.005)$ \\
& & & & \\
Observations & 251,319 & 348,546 & 192,986 & 224,022 \\
Bandwidth & 2.426 & 3.319 & 1.879 & 2.170 \\
Mean of outcome among 26-year-olds & 0.302 & 0.431 & 0.499 & 0.536 \\
\hline
\end{tabular}

Notes: Estimates from local linear regressions using a triangle kernel and optimal bandwidth as defined by Imbens-

Kalyanaraman. Standard errors in parentheses. $* / * * * * *$ denotes significance at the $10 / 5 / 1$ percent level. 
Table 8

Results using Calonico, Cattaneo, and Titunik (2014) robust inference procedure (full sample)

\begin{tabular}{|c|c|c|c|c|}
\hline & $\begin{array}{l}(1) \\
\text { Threat } \\
\text { effect }\end{array}$ & $\begin{array}{l}\text { (2) } \\
\text { Effect within } \\
180 \text { days }\end{array}$ & $\begin{array}{l}(3) \\
\text { Effect within } \\
270 \text { days }\end{array}$ & $\begin{array}{l}\text { (4) } \\
\text { Effect within } \\
365 \text { days }\end{array}$ \\
\hline Effect of program eligibility & $0.0171 * * *$ & $0.0096 * *$ & -0.0040 & $-0.0073 *$ \\
\hline Conventional p-value & 0.000 & 0.011 & 0.382 & 0.074 \\
\hline Robust p-value & 0.002 & 0.012 & 0.899 & 0.709 \\
\hline Observations within bandwidth & 347.032 & 342.191 & 287.712 & 291.949 \\
\hline Bandwidth & 3.078 & 3.039 & 2.579 & 2.614 \\
\hline Mean of outcome among 25 -year-olds & 0.300 & 0.426 & 0.531 & 0.553 \\
\hline
\end{tabular}

Notes: Estimates from local linear regressions using a triangle kernel and optimal bandwidth as defined by Imbens-

Kalyanaraman. $* / * * * * *$ denotes significance at the $10 / 5 / 1$ percent level. 
Table 9

Robustness to changes in the definition of employment (full sample)

\begin{tabular}{|c|c|c|c|}
\hline & $\begin{array}{l}(1) \\
\text { Baseline estimates } \\
\text { (Table } 3 \text {, column 1) }\end{array}$ & $\begin{array}{l}\text { (2) } \\
\text { Stricter } \\
\text { definition of } \\
\text { employment }^{\mathrm{a}} \\
\end{array}$ & $\begin{array}{l}(3) \\
\text { New Start Jobs are } \\
\text { treated as } \\
\text { employment }\end{array}$ \\
\hline A. Threat effect & $\begin{array}{l}0.0171 \text { *** } \\
(0.003)\end{array}$ & $\begin{array}{l}0.0171 \text { *** } \\
(0.003)\end{array}$ & $\begin{array}{l}0.0178 * * * \\
(0.004)\end{array}$ \\
\hline $\begin{array}{l}\text { Observations within bandwidth } \\
\text { Bandwidth } \\
\text { Mean of outcome among } 25 \text { - year-olds }\end{array}$ & $\begin{array}{l}347,032 \\
3.078 \\
0.300\end{array}$ & $\begin{array}{l}351,942 \\
3.119 \\
0.300\end{array}$ & $\begin{array}{l}339,717 \\
3.018 \\
0.301\end{array}$ \\
\hline$B$. Effect within 180 days & $\begin{array}{l}0.0096 * * \\
(0.004)\end{array}$ & $\begin{array}{l}0.0095 * * \\
(0.004)\end{array}$ & $\begin{array}{l}0.0102 * * * \\
(0.004)\end{array}$ \\
\hline $\begin{array}{l}\text { Observations within bandwidth } \\
\text { Bandwidth } \\
\text { Mean of outcome among } 25 \text {-year-olds }\end{array}$ & $\begin{array}{l}342,191 \\
3.039 \\
0.426\end{array}$ & $\begin{array}{l}342,424 \\
3.041 \\
0.426\end{array}$ & $\begin{array}{l}362,867 \\
3.2017 \\
0.431\end{array}$ \\
\hline C. Effect within 270 days & $(0.004)^{-0.0040}$ & $\begin{array}{l}-0.0035 \\
(0.004)\end{array}$ & $\begin{array}{l}-0.00167 \\
(0.004)\end{array}$ \\
\hline $\begin{array}{l}\text { Observations within bandwidth } \\
\text { Bandwidth } \\
\text { Mean of outcome among } 25 \text {-year-olds }\end{array}$ & $\begin{array}{l}287,712 \\
2.579 \\
0.531\end{array}$ & $\begin{array}{l}285,024 \\
2.555 \\
0.494\end{array}$ & $\begin{array}{l}344,362 \\
3.056 \\
0.503\end{array}$ \\
\hline$D$. Effect within 365 days & $\begin{array}{l}-0.0073 * \\
(0.004)\end{array}$ & $\begin{array}{l}-0.0072^{*} \\
(0.004)\end{array}$ & $\begin{array}{l}-0.00275 \\
(0.004)\end{array}$ \\
\hline $\begin{array}{l}\text { Observations within bandwidth } \\
\text { Bandwidth } \\
\text { Mean of outcome among } 25 \text {-year-olds }\end{array}$ & $\begin{array}{l}291,949 \\
2.614 \\
0.553\end{array}$ & $\begin{array}{l}288,055 \\
2,587 \\
0.531\end{array}$ & $\begin{array}{l}293,7871 \\
2.630 \\
0.5420\end{array}$ \\
\hline
\end{tabular}

Notes: Estimates from local linear regressions using a triangle kernel and optimal bandwidth as defined by Imbens-

Kalyanaraman. Standard errors in parentheses. $* / * * / * * *$ denotes significance at the $10 / 5 / 1$ percent level. a. In column

(2) we require spells with temporary, hourly or part-time work to last for at least 60 days to be considered employment, compared to 30 days in our baseline estimates. 
Table 10

Effects on earnings

\begin{tabular}{llllll}
\hline & $\begin{array}{l}(1) \\
\text { Annual } \\
\text { Earnings } \\
(\mathrm{t}+1)\end{array}$ & $\begin{array}{l}(2) \\
\text { Log Annual } \\
\text { Earnings } \\
(\mathrm{t}+1)\end{array}$ & $\begin{array}{l}\text { Annual } \\
\text { Earnings } \\
(\mathrm{t}+2)\end{array}$ & $\begin{array}{l}\text { Log Annual } \\
\text { Earnings } \\
(\mathrm{t}+2)\end{array}$ & $\begin{array}{l}\text { Monthly } \\
\text { Wage } \\
(\mathrm{t}+1)\end{array}$ \\
\hline $\begin{array}{l}\text { Effect of program } \\
\text { eligibility }\end{array}$ & $\begin{array}{l}12.75 \\
(9.735)\end{array}$ & $\begin{array}{l}0.00473 \\
(0.012)\end{array}$ & $\begin{array}{l}-6.572 \\
(11.703)\end{array}$ & $\begin{array}{l}-0.00363 \\
(0.013)\end{array}$ & $\begin{array}{l}-80.31 \\
(56.72)\end{array}$ \\
$\begin{array}{l}\text { Observations within } \\
\text { bandwidth }\end{array}$ & 272,853 & 252,130 & 228,009 & 183,292 & 104,886 \\
$\begin{array}{l}\text { Bandwidth } \\
\begin{array}{l}\text { Mean outcome among } \\
\text { 25-year-olds }\end{array}\end{array}$ & 2.492 & 2.898 & 2.104 & 2.095 & 3.709 \\
\hline
\end{tabular}

Notes: Estimates from local linear regressions using a triangle kernel and optimal bandwidth as defined by Imbens-

Kalyanaraman. Standard errors in parentheses. $* / * * * * *$ denotes significance at the 10/5/1 percent level. Annual earnings (in SEK 100) are measured one and two years after the start of the unemployment spell. Monthly wage is measured in the fall the year after the start of the unemployment spell. 
Table 11

Effects by benefit cut

\begin{tabular}{lllll}
\hline & $\begin{array}{l}(1) \\
\text { Benefit cut } \\
\text { Threat effect }\end{array}$ & $\begin{array}{l}\text { No benefit cut } \\
\text { Threat effect }\end{array}$ & $\begin{array}{l}(3) \\
\text { Benefit cut } \\
\text { Effect within } \\
180 \text { days }\end{array}$ & $\begin{array}{l}\text { (4) } \\
\text { No benefit cut } \\
\text { Effect within } \\
180 \text { days }\end{array}$ \\
\hline $\begin{array}{l}\text { Effect of program } \\
\text { eligibility }\end{array}$ & $\begin{array}{l}0.00912^{* * *} \\
(0.009)\end{array}$ & $\begin{array}{l}0.0177^{* * *} \\
(0.004)\end{array}$ & $\begin{array}{l}0.00497 * * \\
(0.012)\end{array}$ & $\begin{array}{l}0.0109 * * * \\
(0.004)\end{array}$ \\
$\begin{array}{l}\text { Observations within } \\
\text { bandwidth }\end{array}$ & 61,568 & 292,557 & 35,258 & 274,767 \\
$\begin{array}{l}\text { Bandwidth } \\
\text { Mean outcome among } \\
\text { 25-year-olds }\end{array}$ & 3.839 & 3.041 & 2.111 & 2.870 \\
\hline
\end{tabular}

Notes: Estimates from local linear regressions using a triangle kernel and optimal bandwidth as defined by Imbens-

Kalyanaraman. Standard errors in parentheses. $* * * * * * *$ denotes significance at the $10 / 5 / 1$ percent level. 


\section{Appendix A.}

\section{Derivation of the Results in Section II.A.}

To examine how search effort is affected by activation intensity, and how this effect varies across types, equations (1)-(3) in the main text can be rewritten as

$$
\begin{aligned}
& \left(\rho+p_{u e}\right) V^{E}=h\left((1-\tau) w, 1-l_{e}\right)+p_{u e} V^{U}, \\
& \left(\rho+\alpha^{i} s_{u}+p_{a u}\right) V^{U}=h\left((1-\tau) b, 1-s_{u}\right)+\alpha^{i} s_{u} V^{E}+p_{a u} V^{A} \\
& \left(\rho+\alpha^{i} s_{a}\right) V^{A}=h\left((1-\tau) b, 1-s_{a}-l_{a}\right)+\alpha^{i} s_{a} V^{E} .
\end{aligned}
$$

The comparative statics with respect to activation time are

$$
\begin{aligned}
& \frac{\partial V^{A}}{\partial l_{a}}=\frac{-h_{F}^{\prime}}{\left(\rho+\alpha^{i} s_{a}\right)}<0, \\
& \frac{\partial V^{U}}{\partial l_{a}}=\frac{p_{a u}}{\rho+\alpha^{i} s_{u}+p_{a u}} \frac{\partial V^{A}}{\partial l_{a}}<0,
\end{aligned}
$$

where $-h_{F}^{\prime}$ is the derivative of the utility function with respect to leisure time. The individual maximizes her utility by choosing search effort, taking all macro-level variables (such as the job-finding rates $\alpha^{i}$ ) as given. The first-order conditions are

$$
\begin{aligned}
& h_{F}^{\prime}\left((1-\tau) b, 1-s_{u}\right)=\alpha^{i}\left[V^{E}-V^{U}\right], \\
& h_{F}^{\prime}\left((1-\tau) b, 1-s_{a}-l_{a}\right)=\alpha^{i}\left[V^{E}-V^{A}\right] .
\end{aligned}
$$

On the left-hand side of equations (9) and (10), one has the marginal cost of search, whereas the right-hand side captures the marginal benefits of search (the product of the job-finding rate and the value of a job). 
Search effort while the individual is still in open unemployment is determined by (9). Denote the marginal benefit of search while in open unemployment by $B^{U}=\alpha^{i}\left[V^{E}-V^{U}\right]$. We have

$$
\frac{\partial B^{U}}{\partial l_{a}}=\frac{\alpha \partial\left[V^{E}-V^{U}\right]}{\partial l_{a}}=\alpha^{i}\left(\frac{p_{u e}}{\rho+p_{u e}}-1\right) \frac{\partial V^{U}}{\partial l_{a}}>0,
$$

where the second equality follows from (4). That is, the marginal benefit of search increases with the intensity of activation. Next, let us examine how this effect differs by the job arrival rate $\alpha^{i}$. Using (7) and (8), we have

$$
\begin{aligned}
& \frac{\partial B^{U}}{\partial l_{a} \partial \alpha^{i}}=\left(\frac{p_{u e}}{\rho+p_{u e}}-1\right) \frac{\partial V^{U}}{\partial l_{a}}+\alpha^{i}\left(\frac{p_{u e}}{\rho+p_{u e}}-1\right) \frac{\partial}{\partial \alpha^{i}}\left(\frac{p_{a u}}{\rho+\alpha^{i} s_{u}+p_{a u}} \frac{\partial V^{A}}{\partial l_{a}}\right) \\
&=\left(\frac{p_{u e}}{\rho+p_{u e}}-1\right)\left(\frac{p_{a u}}{\rho+\alpha^{i} s_{u}+p_{a u}}\right) \frac{\partial V^{A}}{\partial l_{a}} \\
&-\alpha^{i}\left(\frac{p_{u e}}{\rho+p_{u e}}-1\right) \frac{s_{u} p_{a u}}{\left(\rho+\alpha^{i} s_{u}+p_{a u}\right)^{2}} \frac{\partial V^{A}}{\partial l_{a}} \\
&+\alpha^{i}\left(\frac{p_{u e}}{\rho+p_{u e}}-1\right)\left(\frac{p_{a u}}{\rho+\alpha^{i} s_{u}+p_{a u}} \frac{\partial V^{A}}{\partial l_{a} \partial \alpha^{i}}\right)
\end{aligned}
$$

By collecting terms and adopting the notation $\Gamma=\frac{p_{u e}}{\rho+p_{u e}}-1<0, \Lambda=\frac{p_{a u}}{\rho+\alpha^{i} s_{u}+p_{a u}}>0$ and $\Phi=1-\frac{\alpha s_{u}}{\rho+\alpha^{i}+p_{a u}}>0,(12)$ can be written as

$$
\frac{\partial B^{U}}{\partial l_{a} \partial \alpha^{i}}=\Lambda \Gamma \Phi \frac{\partial V^{A}}{\partial l_{a}}+\alpha^{i} \Lambda \Gamma \frac{\partial V^{A}}{\partial l_{a} \partial \alpha^{i}} .
$$

The first term on the right is positive. The second term is negative, since on the basis of (7), $\frac{\partial V^{A}}{\partial l_{a} \partial \alpha^{i}}=\frac{s_{a} h_{F}^{\prime}}{\left(\rho+\alpha^{i} s_{a}\right)^{2}}>0$. On one hand, a greater job-arrival rate increases the benefit of search, since the probability of getting a job is a product of search and the job arrival rate (the direct 
impact, the first term). On the other hand, people with a greater job arrival rate suffer less from a higher activation intensity, since they exit activation with a higher rate (captured by the cross partial derivative in the second term). This indirect effect moderates the effect of activation on search effort. Activation therefore has a larger effect on the benefits of search for the high type, if the direct effect dominates. This happens when the (negative) impact of activation intensity on utility does not decrease too rapidly with better job-finding ability.

Let us next turn to the benefits of search during the actual activation phase. The marginal benefit of search, which we denote by $B^{A}$ in the case of activation, is then given by the righthand side of (10). We have that

$$
\frac{\partial B^{A}}{\partial l_{a}}=\frac{\alpha \partial\left[V^{E}-V^{A}\right]}{\partial l_{a}}=\alpha^{i}\left(\frac{p_{u e}}{\rho+p_{u e}} \frac{p_{a u}}{\rho+\alpha^{i} s_{u}+p_{a u}}-1\right) \frac{\partial V^{A}}{\partial l_{a}}>0,
$$

where the latter equality again follows from (4) and (8). Differentiating the above expression with respect to $\alpha^{i}$ yields

$$
\begin{aligned}
& \frac{\partial B^{A}}{\partial l_{a} \partial \alpha^{i}}=\left(\frac{p_{u e}}{\rho+p_{u e}} \frac{p_{a u}}{\rho+\alpha^{i} s_{u}+p_{a u}}-1\right) \frac{\partial V^{A}}{\partial l_{a}}-\alpha^{i} \frac{\left(\rho+p_{u e}\right) p_{u e} p_{a u} s_{u}}{\left(\rho+p_{u e}\right)^{2}\left(\rho+\alpha^{i} s_{u}+p_{a u}\right)^{2}} \frac{\partial V^{A}}{\partial l_{a}}+ \\
& \alpha^{i}\left(\frac{p_{u e}}{\rho+p_{u e}} \frac{p_{a u}}{\rho+\alpha^{i} s_{u}+p_{a u}}-1\right) \frac{\partial V^{A}}{\partial l_{a} \partial \alpha^{i}} .
\end{aligned}
$$

The first two terms on the right-hand side are positive while the third is negative. Again, the benefit of search is increasing in the job-arrival rate if the second derivative, $\frac{\partial V^{A}}{\partial l_{a} \partial \alpha^{i}}$, is not too large. 


\section{Appendix B}

\section{Additional Tables and Figures}
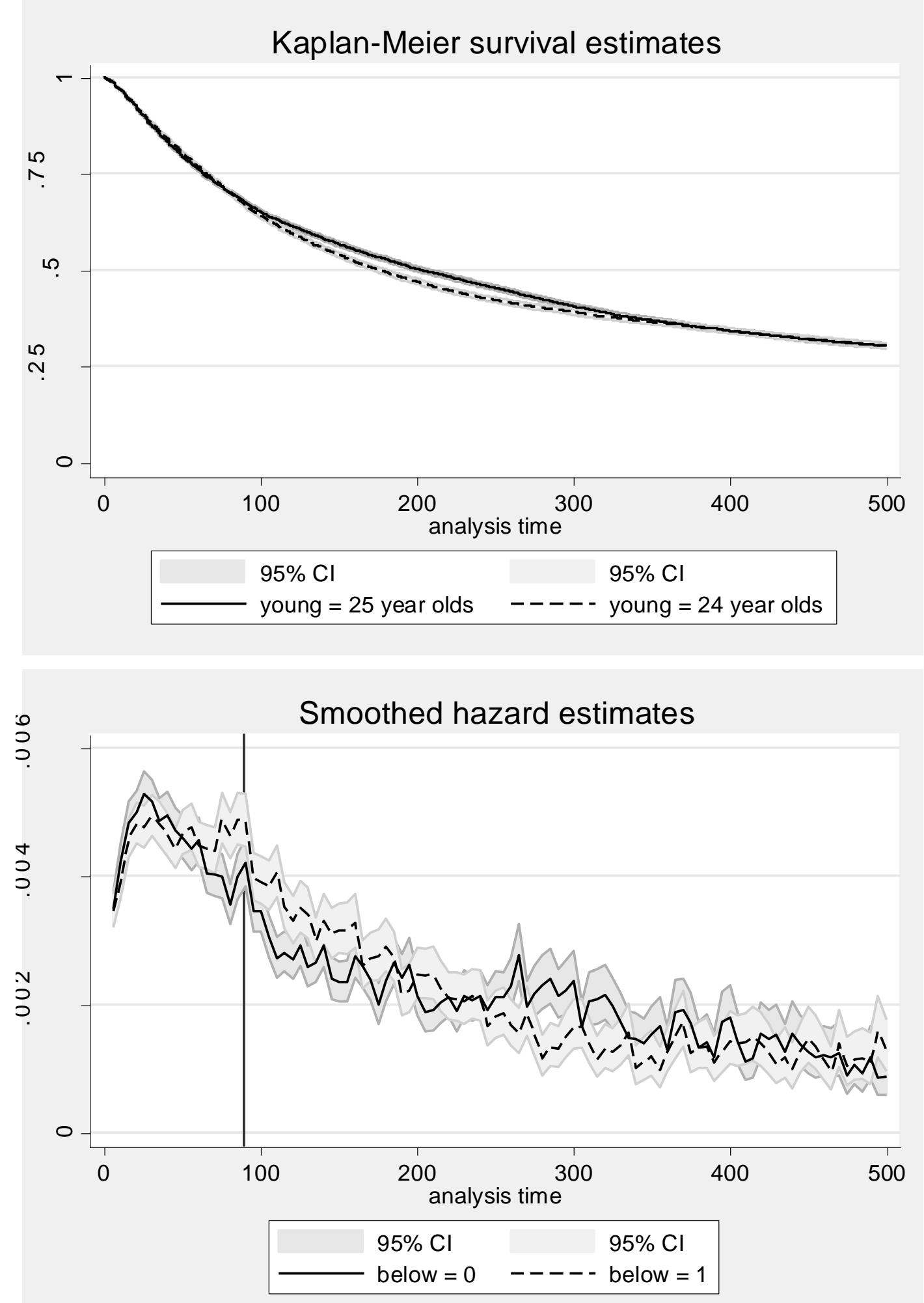

Figure B.1: Kaplan-Meier survival estimates for unemployment duration (upper panel) and smoothed hazard estimates for exits to employment (lower panel) for 24- and 25-year-olds in 2008 - 2010. 
Note: The individuals are divided into groups based on their age 90 days after entering unemployment. The sample is limited to 24- and 25-year-olds born in the same calendar year.
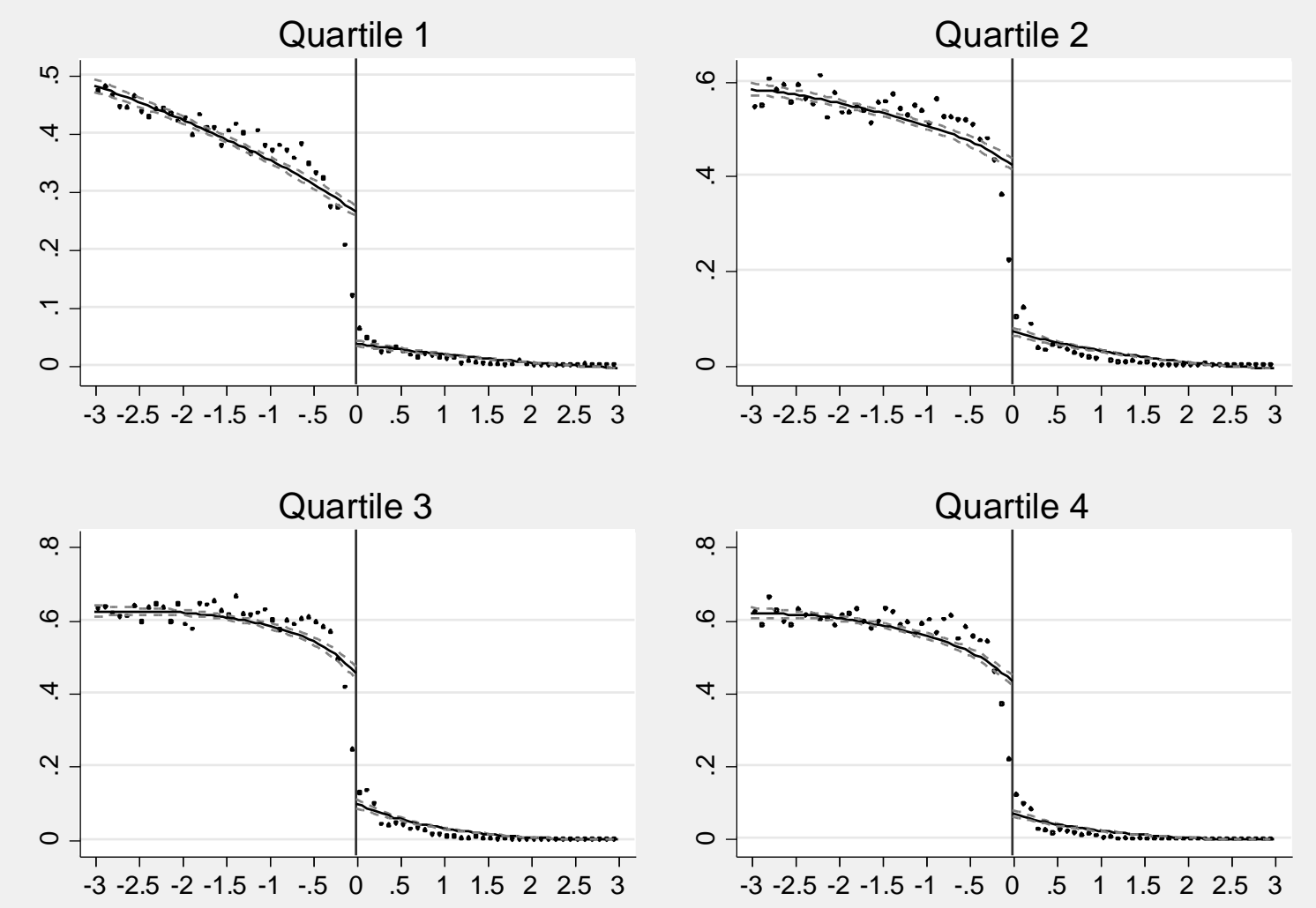

Figure B.2: Youth Job Guarantee take-up by quartiles of predicted employment probabilities (among individuals whose unemployment spell lasted longer than 90 days)

Note: Age in years relative to the cut-off age of 25 on the x-axes and an indicator for participating in the program on the y-axes. Age refers to the individual's age 90 days after entering unemployment. 
Table B. 1

Characteristics of the unemployed by employment probability quartiles.

\begin{tabular}{|c|c|c|c|c|}
\hline & $\begin{array}{c}(1) \\
\text { Quartile } 1\end{array}$ & $\begin{array}{c}(2) \\
\text { Quartile } 2\end{array}$ & $\begin{array}{c}(3) \\
\text { Quartile } 3\end{array}$ & $\begin{array}{c}(4) \\
\text { Quartile } 4\end{array}$ \\
\hline Country of birth, non-Nordic & 0.480 & 0.205 & 0.109 & 0.039 \\
\hline $\begin{array}{l}\text { Has not completed upper secondary } \\
\text { school }\end{array}$ & 0.500 & 0.163 & 0.066 & 0.025 \\
\hline Received social assistance & 0.455 & 0.168 & 0.073 & 0.025 \\
\hline Has a child & 0.225 & 0.119 & 0.093 & 0.053 \\
\hline Registered disability & 0.181 & 0.030 & 0.009 & 0.002 \\
\hline Had a neurological drug & 0.233 & 0.139 & 0.129 & 0.077 \\
\hline Was treated at a hospital & 0.411 & 0.336 & 0.331 & 0.290 \\
\hline Had more than two medicines & 0.262 & 0.246 & 0.264 & 0.270 \\
\hline Received sickness benefits & 0.050 & 0.055 & 0.068 & 0.056 \\
\hline Was a psychiatric patient & 0.121 & 0.044 & 0.027 & 0.010 \\
\hline Had a drug for mental illness & 0.166 & 0.083 & 0.068 & 0.036 \\
\hline Received disability pension & 0.059 & 0.003 & 0.001 & 0.000 \\
\hline
\end{tabular}

Notes: Background variables are measured in the previous year or at the start of the unemployment spell, except for has child, which is measured in 2007.

Table B.2

Fuzzy RD estimates as a function of bandwidth

\begin{tabular}{lllll}
\hline & \multicolumn{2}{c}{ Threat effect } & \multicolumn{2}{c}{ Effect days 1-180 } \\
\hline $\begin{array}{l}\text { Percentage of } \\
\text { optimal bandwidth }\end{array}$ & Coefficient & $\begin{array}{l}\text { Standard } \\
\text { error }\end{array}$ & Coefficient & $\begin{array}{l}\text { Standard } \\
\text { error }\end{array}$ \\
\hline 10 & 0.186952 & 0.841376 & 1.29486 & 1.192799 \\
20 & 0.252464 & 0.157076 & 0.419813 & 0.177366 \\
30 & 0.168599 & 0.075067 & 0.201062 & 0.082276 \\
40 & 0.13639 & 0.049062 & 0.138902 & 0.053439 \\
50 & 0.123754 & 0.037256 & 0.106362 & 0.040368 \\
60 & 0.110597 & 0.030437 & 0.084841 & 0.03293 \\
70 & 0.097306 & 0.025796 & 0.067739 & 0.027899 \\
80 & 0.09321 & 0.022574 & 0.058267 & 0.024376 \\
90 & 0.092001 & 0.020173 & 0.054019 & 0.021764 \\
100 & 0.08921 & 0.0183 & 0.049992 & 0.019732 \\
\hline
\end{tabular}


${ }^{1}$ We discuss related literature more extensively in Section II.
${ }^{2}$ Cuff (2000) discusses the role of workfare in screening between the "deserving" and "undeserving" poor in a model where individuals differ (in addition to ability) in their disutility of work.

${ }^{3}$ Note that high-type individuals will naturally exit unemployment sooner than low-type individuals, ceteris paribus, even in the absence of activation. What we are interested in, however, is how an activation program affects the search behavior of different types of workers, i.e. whether changes in exit rates from unemployment after the introduction of the policy differ across types.

${ }^{4}$ For example, in Fredriksson and Holmlund (2006a), workfare achieves perfect screening between non-workers and workers (i.e. only workers claim unemployment insurance benefits), but it may still not be the optimal policy as other policy instruments yield higher welfare. In our case, activation increases the benefits of search for both types, but more so for the high type; in this sense, screening is less than perfect. Another example of imperfect screening, albeit in a very different context, arises in optimal tax models where workers with different abilities choose different levels of work hours.

${ }^{55}$ Hall (2005) discusses sticky wages as a reason behind aggregate fluctuations in firm recruitment effort and job-finding rates. We conjecture that a similar mechanism might explain variation in job-finding probabilities within the population.

${ }^{6}$ Besley and Coate (1992) discuss the deterrent effect of workfare, which relates to encouraging povertyreducing investment. Participation in activation can also be seen as an investment that helps the individual find a job later on; however, in our context this should not be seen as a deterrent effect to the extent that unemployment is involuntary.

${ }^{7}$ If people also differed with respect to the discount rate, it could well be the case that people with a high jobfinding rate discount the future less, a situation that would further strengthen the pattern. DellaVigna and Paserman (2005) study the relationship between patience and job search effort, but they do not consider the role of activation.

${ }^{8}$ Rosholm and Svarer (2008) find that there is a strong threat effect from ALMP, but not for the long-term unemployed; this may be related to the notion of individuals in a poor labor market position not reacting to the threat of activation. Bergemann et al. (2011) examine, in turn, whether responses to the threat effect vary according to ethnicity. 
${ }^{9}$ Hämäläinen, Hämäläinen, and Tuomala (2014) are also interested in the health of job-seekers. The difference is that they use subsequent mental health as an additional outcome variable, whereas we concentrate on heterogeneous treatment impacts.

${ }^{10}$ Some rules of the program have changed over time. We describe the rules in place during the time period we study.

${ }^{11}$ The maximum duration in the program is 15 months. Individuals who are still unemployed after 15 months are transferred to another activation program (the Job and Development Guarantee), which is aimed at long-term unemployed of all ages.

${ }^{12}$ Until the end of 2006, unemployed youth were assigned to activities organized by the municipalities (mainly training or work placement) within the programs Youth Guarantee (20-24-year-olds) and the Municipality Youth Program (18-19-year olds); see Carling and Larsson (2005) and Forslund and Nordström Skans (2006) for evaluations of the previous youth programs.

${ }^{13}$ The working condition restricts UI benefits to individuals who have worked, at least part time, for 6 out of the last 12 months prior to unemployment.

${ }^{14}$ Refers to cases where the individual has been admitted to a hospital. In general, this means that an overnight stay has been required.

15 The hospital registers cover both public and privately operated health care and include ICD codes for diagnoses.

${ }^{16}$ Individuals below age 30 are entitled to financial support if they are unable to work due to their functional impairment for at least a year.

${ }^{17}$ After 2010, the age discontinuity in program eligibility was made less stringent, and hence the latter years cannot be used in an RD analysis.

${ }^{18}$ In Section V.D.5 we check whether our results are robust to alternative definitions of employment.

${ }^{19}$ Individuals are likely to be informed about the program upon registration at the PES and/or during their first meeting with a caseworker, which should take place within 30 days of unemployment. However, individuals can also learn about the program from information sheets available at the PES as well as from the PES website.

${ }^{20}$ Note that this type of response is unlikely among UI recipients as registration at the PES is required in order to receive UI benefits. 
${ }^{21}$ McCrary (2008) develops a formal test of the null hypothesis of continuity of the density of the assignment variable at the cut-off, against the alternative hypothesis that there is jump in the density function at that point. We cannot reject the null; the test statistic has a value of 0.0045 and a standard error of 0.0103 .

${ }^{22}$ In Section VI, where we carry out a benefit-cost analysis of the program, we estimate the full time profile of effects at different points in time during the unemployment spell.

${ }^{23}$ There are several different ways of calculating the optimal bandwidth in an RD design, with no clear consensus on which is best. We analyze the robustness of our results to a wide variety of bandwidths in Section V.D.

${ }^{24}$ The problem noted by Abadie, Chingos, and West (2016) would arise if the prediction model were estimated on control group data and then used to form predictions for both the treatment and the control group. This would lead to over-fitting of observations in the control group. In our case, both the control group and treatment group data come from 2008-2010, whereas the prediction model is estimated on data on unemployment spells in 2007. Nekoei and Weber (2017) use a similar procedure to avoid the problem of over-fitting.

${ }^{25}$ Also in quartile 1, the relative "effect" is of the same magnitude, but we would not conclude that there is an effect in the $1^{\text {st }}$ quartile. As noted above, the estimated effect itself is very small and far from being statistically significant, and the magnitude of the relative effect is driven by dividing this estimate by a small number, i.e. the baseline job-finding rate in the $1^{\text {st }}$ quartile. Note also that, if anything, one would expect the relative effect to be largest for the first quartile, if the individuals in the first quartile were to react at all: as the baseline job-finding rate is very low (10\% in the first 90 days of the unemployment spell), there should be ample room for policy interventions to have an effect.

${ }^{26}$ The dummy for disability pension (early retirement) is not included in the figures for quartile 4 , as there are too few individuals in this quartile with disability pension to run an RD analysis. The dummy is however included as a control in the analysis with covariates for all quartiles.

${ }^{27}$ Until the end of 2006, unemployed 20-24-year-olds were assigned to activities organized by the municipalities within the program Youth Guarantee. The Youth Guarantee was still in place during 2007, but no new unemployed individuals should have been assigned to this program after the end of 2006.

${ }^{28}$ The finding that the effects of program eligibility go toward zero for the smallest bandwidths (i.e. very close to the threshold) has a natural explanation in our case: this is explained by the behavior of take-up close to the threshold. Given that there is only a fairly small jump in take-up at the threshold, it would be surprising if we were to find large effects there. This conjecture is supported by the following finding: If we take into account 
incomplete take-up and examine the robustness of the Wald estimates from the fuzzy RD design (reported at the end of Section V.B), the point estimates do not decline at small bandwidths. (see Table B.2).

${ }^{29}$ Since the wage data cover the whole public sector but only about $50 \%$ of employees in the private sector, the estimates of wages may be biased if program eligibility affects the probability of working in the private sector. The estimates of total earnings do not have this problem as we have earnings for the entire Swedish population. ${ }^{30}$ See Maibom, Rosholm, and Svarer (2017) for a similar cost-benefit analysis of an active labor market policy. ${ }^{31}$ This procedure essentially traces out the difference between the survival functions at each point in time between those eligible for the program vs. those who are not, with the integral of the survival function providing an estimate of the average duration of unemployment.

${ }^{32}$ All numbers cited in this section are measured in SEK at 2009 value.

${ }^{33}$ Payroll taxes (for the relevant age group) corresponded to $21.31 \%$ for 2008 and were reduced to $15.49 \%$ for 2009-2010. Based on figures in Pirttilä and Selin (2011) as well as Edmark et al (2012), the average tax rate for individuals with this level of earnings was around 23\%. Like Maibom, Rosholm, and Svarer (2017), we assume that all gains from increased production accrue to the employees and we do not consider potential increases in revenues from taxation of firms. We also neglect the fact that income changes may affect consumption and thus tax payments to the government through value-added taxes.

${ }^{34}$ More specifically, we use information from the first UI payment occurring within the first three months after registration at the PES. Individuals who do not receive any UI payment within this time interval are given the value zero. Note that we do not take into account potential reductions in social assistance, which we have no detailed information on.

${ }^{35}$ Email correspondence with Jan Norberg, Arbetsförmedlingen 2019-05-24. 